ANL-5907

Instruments

(TID-4500, 14th Ed.)

AEC Research and

Development Report

ARGONNE NATIONAL LABORATORY

P. O. Box 299

Lemont, Illinois

THE ARGONNE 60-INCH CYCLOTRON

by

W. J. Ramler and G. W. Parker

Chemistry Division

February, 1959

Operated by The University of Chicago under

Contract W-31-109-eng-38 


\section{DISCLAIMER}

This report was prepared as an account of work sponsored by an agency of the United States Government. Neither the United States Government nor any agency Thereof, nor any of their employees, makes any warranty, express or implied, or assumes any legal liability or responsibility for the accuracy, completeness, or usefulness of any information, apparatus, product, or process disclosed, or represents that its use would not infringe privately owned rights. Reference herein to any specific commercial product, process, or service by trade name, trademark, manufacturer, or otherwise does not necessarily constitute or imply its endorsement, recommendation, or favoring by the United States Government or any agency thereof. The views and opinions of authors expressed herein do not necessarily state or reflect those of the United States Government or any agency thereof. 


\section{DISCLAIMER}

Portions of this document may be illegible in electronic image products. Images are produced from the best available original document. 


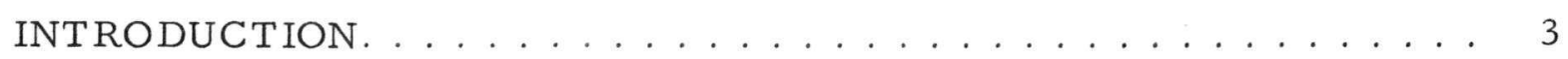

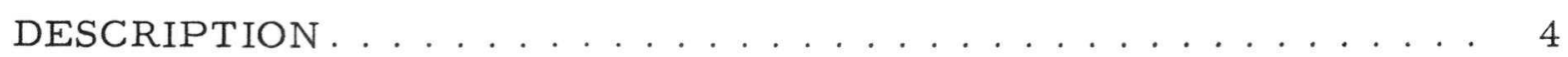

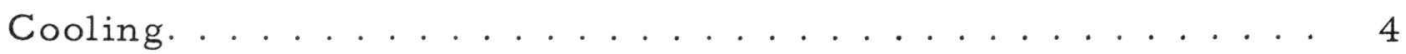

Vacuum ........................... 4

Magnet. . . . . . . . . . . . . . . . . . . . 8

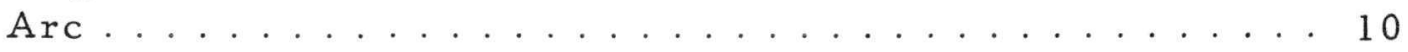

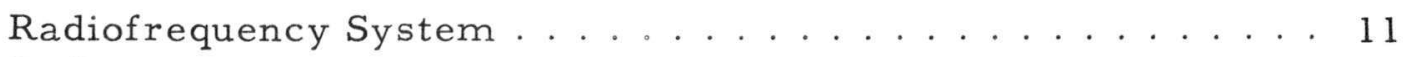

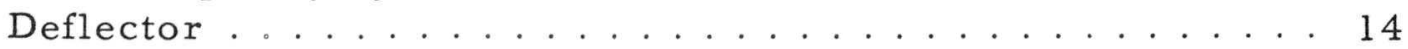

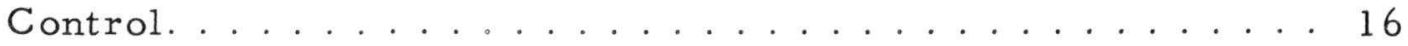

OPERATION AND BEAM CHARACTERISTICS. . . . . . . . . . 16

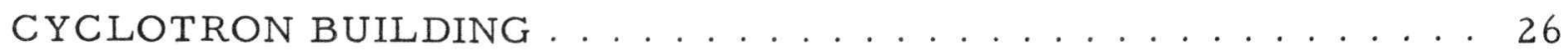

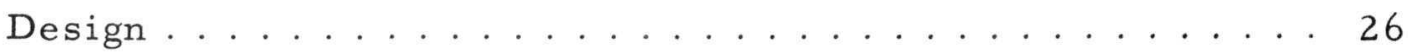

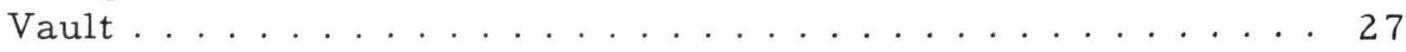

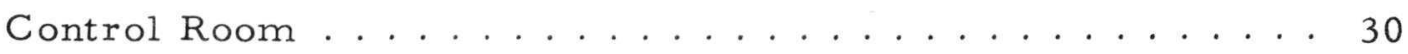

Electrical Equipment Room . . . . . . . . . . . . 30

Mechanical Equipment Room ............... 31

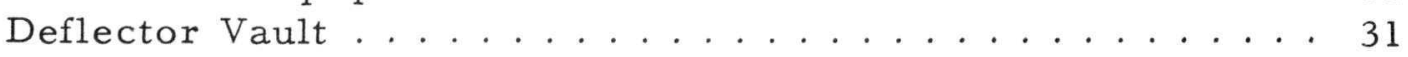

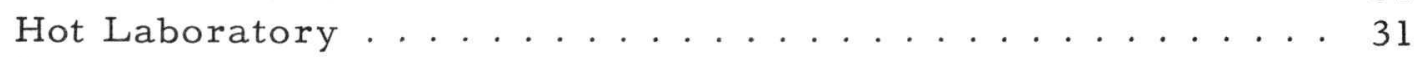

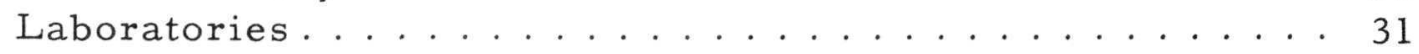

Experimental Tunnel. . . . . . . . . . . . . . 31

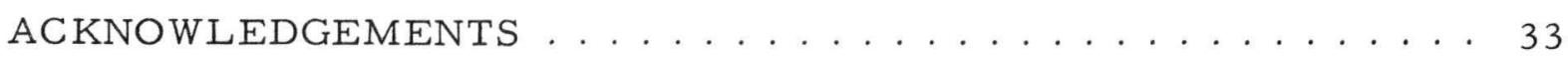

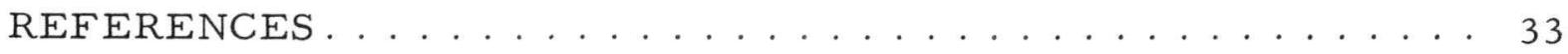

APPENDIX I: ARGONNE CYCLOTRON SUMMARY . . . . . . . . . . 34

APPENDIX II: SUPPLIERS AND FABRICATORS . . . . . . . . . . 37 


\title{
THE ARGONNE 60-INCH CYCLOTRON
}

\author{
W. J. Ramler and G. W. Parker
}

\section{INTRODUCTION}

The constant-frequency, sixty-inch cyclotron is an experimental facility to aid basic research sponsored by the Argonne National Laboratory and by the Associated Midwestern Universities. This machine has been in productive operation since July 10,1952. Throughout this period the operational requirements have been extremely diversified. Deflected beams of deuterons, helium ions, singly-charged hydrogen molecules and neutrons of a broad energy spectrum are constantly in demand. The irradiations have encompassed the fields of heavy element chemistry, nuclear activation studies, nuclear scattering, solid state physics, radiation chemistry, isotope production, and biological studies.

The cyclotron was purchased from the Collins Radio Company, Cedar Rapids, Iowa, under a fixed sum, time limit, performance specification contract. Design and construction was initiated June 17, 1949, and the cyclotron was accepted by the Laboratory July 10, 1952. The supplier conformed to the contract time limit and adequately met all of the stringent contract specifications.

The performance of the machine was governed by the following deflected deuteron beam specifications: (1) beam energy to be at least $21 \mathrm{Mev}$; (2) total current not less than $200 \mu \mathrm{amp}$, with continuous operation for 22 out of 24 hours; (3) $20 \%$ of the total beam to lie within an area of $2 \mathrm{~cm}^{2}$; (4) $50 \%$ of the beam to be within $\pm 5 \%$ of the mean value of the beam energy, and (5) the beam intensity and energy to be constant to within $\pm 5 \%$ averaged over one-minute intervals for at least a four-hour period. In addition, capacities of the power supplies, the magnet and the radiofrequency ( $\mathrm{rf}$ ) system were so sized to facilitate future conversion of the accelerator to 35-Mev deuteron beam operation.

Particle acceleration was initiated October 30,1951 and within one hour a 21 - Mev deuteron circulating beam of $15 \mu \mathrm{amp}$ was measured. This accomplishment was closely followed by the extraction of the circulating beam; the following is a brief historical log.

Nov. 20, 1951 - $10 \mu$ amp deflected

Nov. 30, $1951-100 \mu$ amp deflected

Dec. 15, 1951 - $150 \mu$ amp deflected 
Dec. $21,1951-200+\mu$ amp deflected

Jan. 31, 1952 - $120 \mu \mathrm{amp}$ deflected-continuous operation for 24 hours

May 29, 1952 - $235 \mu$ amp deflected - continuous operation for 24 hours

July 10, 1952 - ANL acceptance

The ANL cyclotron has never been characterized in the literature and it is the purpose of this writing to describe the accelerator, its operating characteristics, and the housing with its associated facilities.

\section{DESCRIPTION}

To consider the cyclotron and its performance, it is necessary to consider the systems which make it possible to accelerate and deflect the charged particles. The discussion that follows will be sectionalized as to operating systems.

\section{$\underline{\text { Cooling }}$}

Liquid cooling of the operating systems is obtained by circulation of demineralized water through the cyclotron and, in turn, through a tubeand-shell heat exchanger of which the shell side is connected to an outside cooling tower. The circulating pumps and heat exchanger are sized to handle a $1000-\mathrm{kw}$ heat load, with the normal operating load being about $300 \mathrm{kw}$. The cooling tower design is also based upon a heat load of $1000 \mathrm{kw}$ and is such that a $10^{\circ} \mathrm{F}$ water temperature differential can be obtained for a $78^{\circ}$ wet bulb with a $1200-\mathrm{gpm}$ flow rate through the tower. The coolant flow rate is normally $300 \mathrm{gpm}$ at $80 \mathrm{psi}$. The conductivity is maintained at 10 micromhos or less, with a $\mathrm{pH}$ of about seven. Dee system water temperature stability of $1^{\circ} \mathrm{F}$ or better is required for steady operation.

\section{Vacuum}

The physical dimensions and types of materials used are governed both by the rf system and vacuum techniques. The main vacuum system consists of 6 basic parts: the mechanical pumps, diffusion pumps, vacuum take-off box (VTO), "obround," transition section, and acceleration chamber. The transition section and acceleration chamber are mounted in a fixed position; the VTO box and obround are mounted on a motor-driven carriage which operates on a rail system. This permits the removal of the dee heads from the acceleration chamber and transition section to facilitate maintenance or modification of the dees, deflector system, or ion-source extraction feelers. Mechanical alignment of the system is maintained by the use of one grooved rail and a matching tongue on the carriage wheels. 
The mechanical vacuum pumps, with capacities of $100 \mathrm{cfm}$ and $300 \mathrm{cfm}$, are located in the mechanical equipment room to minimize the noise in the cyclotron area. The 300-cfm pump is used for the roughing of the tank, and the 100-cfm pump is used for the backing of the diffusion pumps. During normal operation, both units are used for backing. Two 6 -inch diameter lines connect these pumps to the forvac manifold of the two diffusion pumps located in the vault.

The two 16-inch oil diffusion pumps were built as a packaged unit, with each pump having remotely air-operated forvac and hivac valves. These pumps are close-coupled to the vacuum tank and have common connections at both the hivac and forvac manifolds. The entire assembly is mounted on wheels, allowing the pumps to be rolled away from the main tank for maintenance or repair purposes.

The diffusion pump baffles, located between the pumps and the 16-inch valves, are cooled by Freon 22 and operate at approximately $-30^{\circ} \mathrm{F}$. In addition, the manifold section has a removable cold trap for liquid $\mathrm{N}_{2}$. This trap is never used during routine operations; however, it is quite useful for vacuum test purposes.

At the normal operating vacuum of $3 \times 10^{-6} \mathrm{~mm} \mathrm{Hg}$, the combined pumping speed of the diffusion pumps is $3000 \mathrm{l} / \mathrm{sec}$. This speed increases to $5000 \mathrm{l} / \mathrm{sec}$ at $1 \times 10^{-5} \mathrm{~mm} \mathrm{Hg}$ and reaches a maximum of $6000 \mathrm{l} / \mathrm{sec}$ at $2 \times 10^{-4} \mathrm{~mm} \mathrm{Hg}$. Such a pumping characteristic enables the system to quickly recover from an operating gas burst. These pumping rates are maintained for forvac pressures up to 100 microns.

The pump manifold connects to the VTO box, which is of welded steel construction ( $47 \times 88 \frac{1}{2} \times 57 \frac{1}{2}$ inches) with internal bracing to withstand atmospheric pressure. Seam welds are continuous, with welding only on the atmosphere side. The internal braces are stagger welded to keep virtual leaks at a minimum. The VTO box contains the gimbal mountings for the cantilever suspension of the dee stems.

The obround is a 66-inch long unit with a cross section that is essentially two half-cylinders of 20 -inch radius separated and connected by flat parallel sides, $37 \frac{1}{2}$ inches in length (see Figs. 1 and 2). This unit is constructed of $1 / 4$-inch thick OFHC copper, rolled into the proper shape with the seams welded with a shielded arc using "Everdur" as a filler rod. A steel framework is welded to the external side of the copper for support of the tank when evacuated. Cooling of this shield is obtained with several loops of 3/8-inch tubing, soft soldered to the copper. On the top of the obround, five pairs of holes are provided for rf power feed-thru to the dee system. 


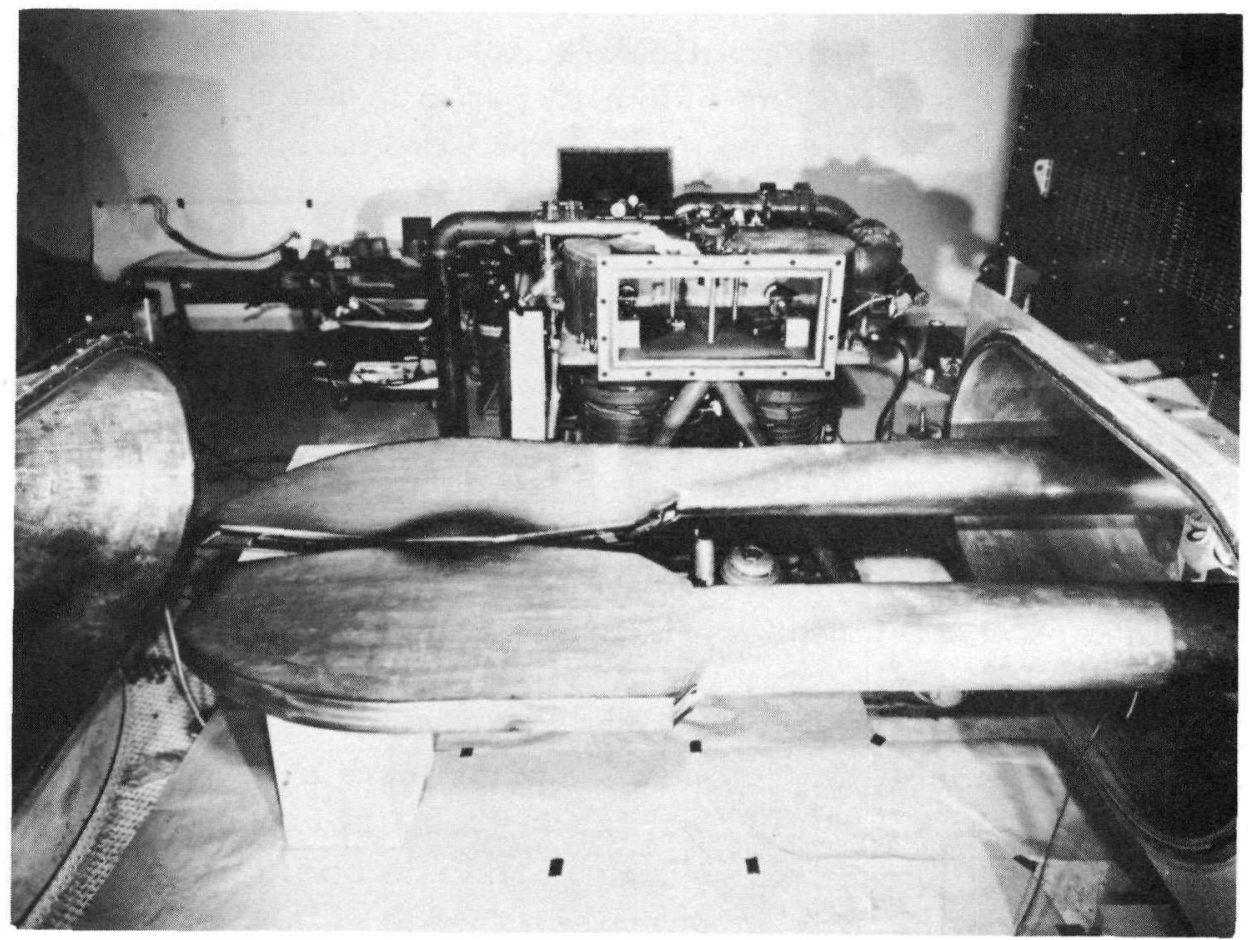

Fig. l Cyclotron dees pulled out of the acceleration chamber. Diffusion pumps and hivac manifold are in the background.

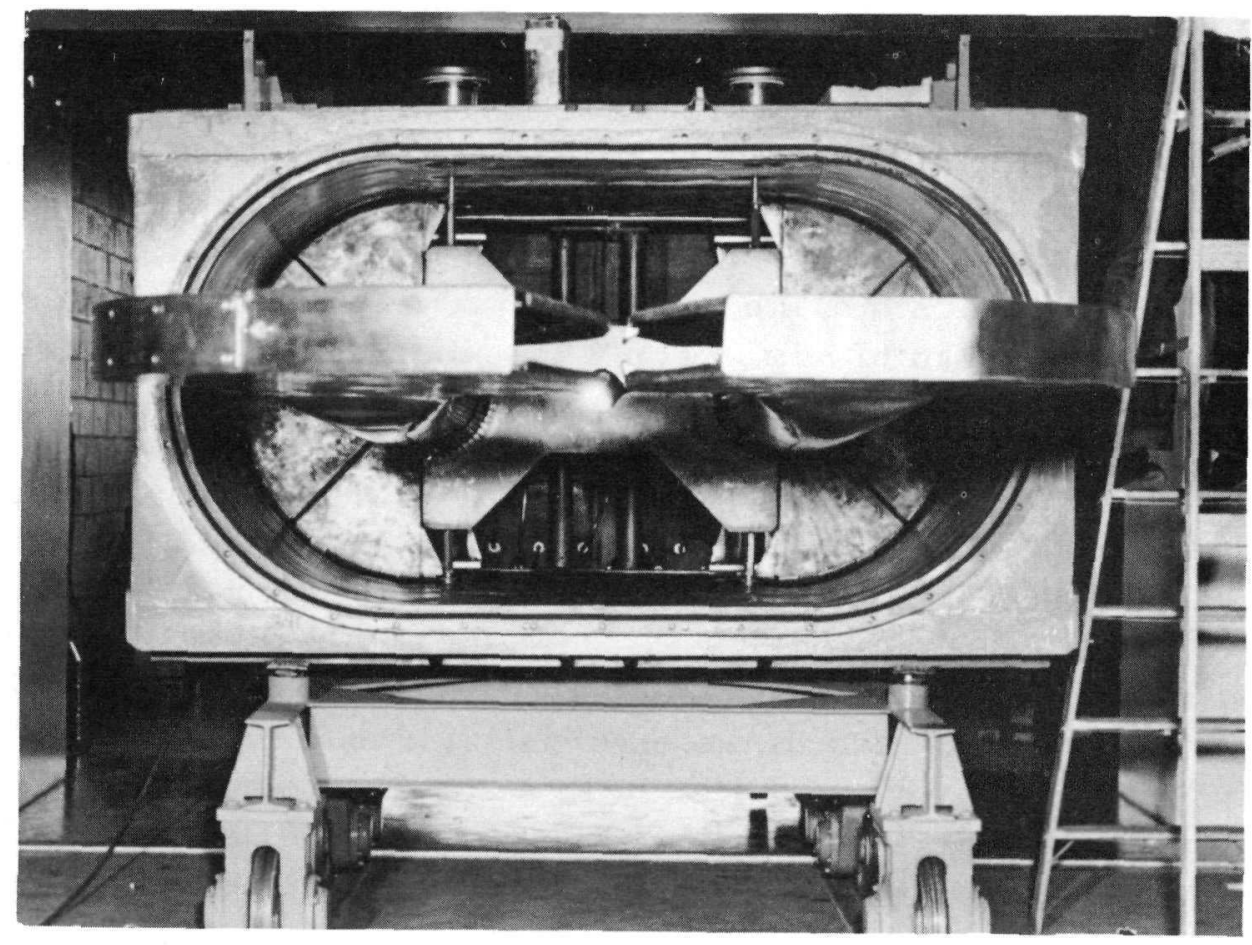

Fig. 2 Radiofrequency shorting bar in position with respect to the dees and the obround ground shield. 
The transition section is 47 inches long and, by means of a taper, makes the transition from the cross section of the obround to the rectangular cross section of the acceleration chamber. The method of construction is similar to the obround and, since the position of this section is in the magnetic field, the framework and flanges are of nonmagnetic type 347 stainless steel.

The acceleration chamber is a composite unit with the basic structure of special 16-14 chrome nickel nonmagnetic stainless steel. The top and bottom portion is a circular opening, 60 inches in diameter, and sealed with discs (lids) of magnet steel to shorten the magnet pole gap. The vertical sides are closed by the transition section, the dee trimmer condenser, the target gate and closure plate, the arc source and the liner water tube closure plate. The inside is lined with water-cooled copper liners to complete the rf shielding circuit.

The vacuum rf seal between the obround and transition sections is accomplished by inserting a gasket ring of matching geometry between each section. This ring is of cold-rolled steel, copper plated, with a groove on each face in which a square-type neoprene gasket is inserted. To obtain the rf seal, numerous annealed copper strips, 1 x 0.012 inch; are first placed into the groove, with an excess of material extending in towards the vacuum. The gasket is inserted over the copper and the strips bent back over the gasket so that approximately one-half the width is covered. When the ring is in place, these fingers mate with the copper covering the end flanges of each section. This sealing technique was also used for the other sections of the vacuum envelope.

In July 1957, after 6 years of operation, it was required to remove the dees from the acceleration chamber, thereby requiring the breaking of the obround-transition seal. The seal did not show any evidence of heating and was re-used in the closing of the chamber. The operation that followed was quite normal.

The total volume of the vacuum system is $\sim 300$ cubic feet. Normal operating pressures are 2 to $9 \times 10^{-6} \mathrm{~mm} \mathrm{Hg}$, with the upper value limited by the operation of the rf system. The pressure of the system is monitored with an RCA 1949 ionization gauge; the indicating device for this gauge provides an interlock for system circuits such as the arc, deflector and oscillator. An additional interlock chain, consisting of thermocouple gauges and a Geisler circuit, is provided to protect the pumps and ion gauges from a system leak. Valves are actuated by compressed air, and, upon power failure, the system will fail safe. The vacuum map for the system is shown in Fig. 3 . 


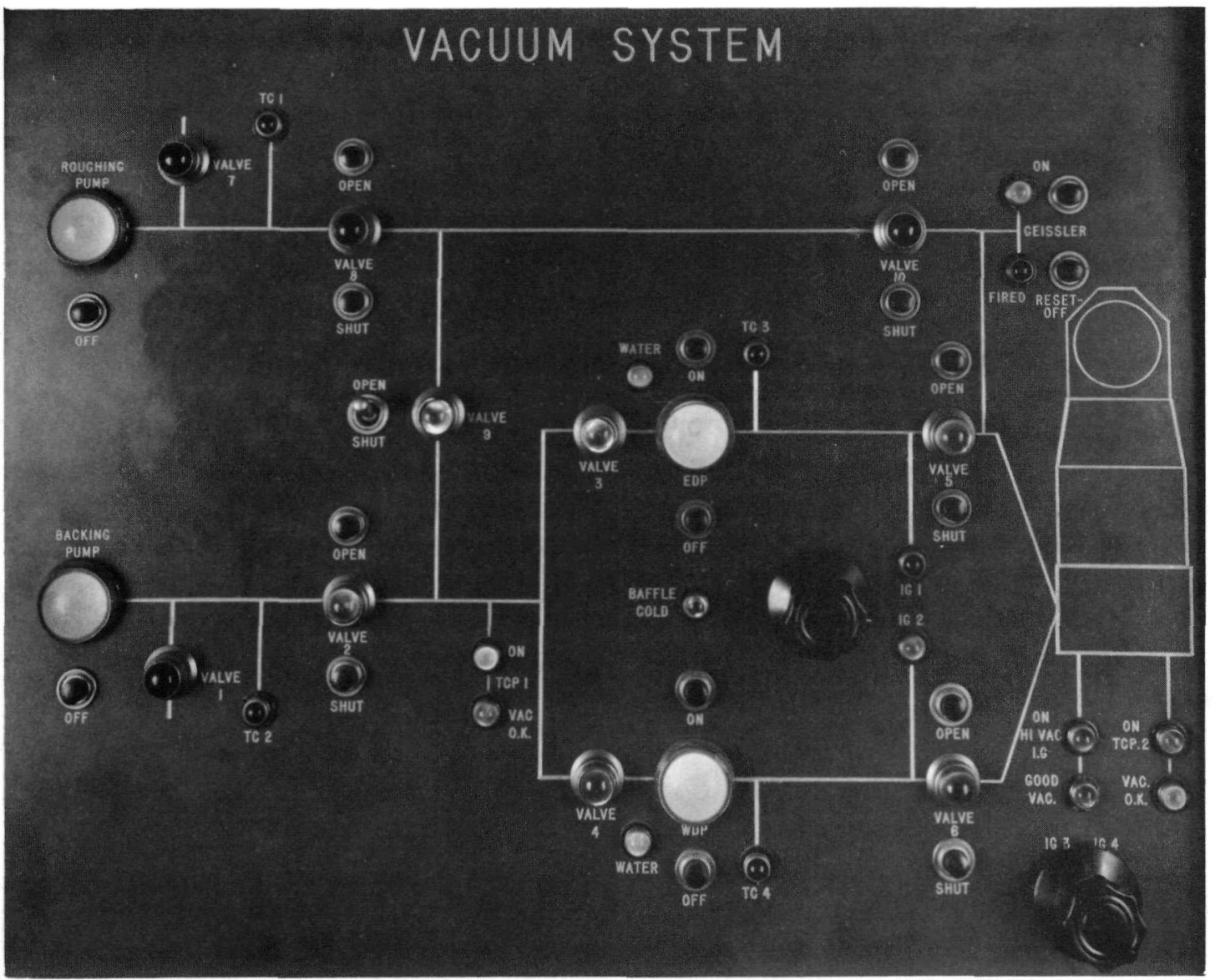

Fig. 3. Cyclotron vacuum map.

Magnet

The electromagnet, 265 tons in weight, is of a standard "double yoke" design, 206 inches long, 164 inches high, and $74 \frac{3}{8}$ inches wide. The diameter of the pole base is $74 \frac{3}{8}$ inches and the diameter of the pole face is 62 inches. The pole gap is twenty-two inches, and, for any given radius, the gap variation is less than 0.005 inch. The 22 -inch air gap, excluding shimming, is reduced to 12 inches by the 5 -inch thick, 60 -inch diameter, top and bottom lids of the acceleration chamber. This 12 -inch dimension is made up of the two 1 -inch gaps between the lids and pole faces, and the 10-inch spacing for the acceleration chamber. Upon installation of Rose rings and rf liners the acceleration chamber gap is reduced to 9 inches.

Magnetic shimming consists of internal Rose rings and external stepped shims. The internal rings are fastened to both the top and bottom lids and are radially located at 26 inches and extend outward to 30 inches. The rings are $1 / 4$ inch thick and 2 inches wide. External top and bottom 
shimming consists of a pyramid of twelve discs, each $1 / 16$ inch thick and of the following radii: 2 of 20 inches; 2 of 16 inches; 2 of 10 inches; 2 of 6 inches; 2 of 4 inches; and 2 of 3 inches. The largest disc is located in contact with the lid.

The magnet yoke, poles and tips, acceleration chamber lids, and shims are of soft iron forgings with the impurity analysis as follows:

$\begin{array}{llll}\text { Carbon } & 0.12 \% & \text { Sulphur } & 0.024 \\ \text { Silicon } & 0.17 & \text { Manganese } & 0.39 \\ \text { Phosphorus } & 0.014 & & \end{array}$

The two magnet coils, totaling 26 tons in weight, are of extruded is aluminum strap, $2 \frac{7}{8} \times 1 / 2$ inches, with a hollow core of $1 / 4 \times 1$ inch through which passes the water coolant. Each coil consists of 10 pancakes, approximately 55 turns per pancake, or a total of 1099 turns for both coils. Each pancake consists of one continuous length of conductor, 1550 feet long. Insulation between turns consists of 2 layers of 0.005-inch Fish paper impregnated with red Glyptal. The insulation between pancakes consists of 2 layers of Bakelite and Glyptal, each layer $1 / 32$ inch thick. All windings are connected in series by uncooled aluminum strap, heli-arc welded to the conductors. The coils are electrically connected in series,



Fig. 4

Magnetization curve for the 60 inch cyclotron magnet. with all hydraulic connections in parallel. The total resistance for both coils is about $0.3 \mathrm{ohm}$. For mechanical stability protection, the coil windings are solidly clamped between two annular $1 \frac{1}{2}$-inch thick aluminum end plates. The over-all dimensions of a completed coil are: $O D=142$ inches, $I D=74 \frac{7}{8}$ inches, and a height of 32.5 inches.

Magnet excitation is provided by a $300-\mathrm{kw}, 355-\mathrm{v}$ (DC) generator, driven by a $450-\mathrm{hp}, 2400$ - volt synchronous motor. The operating field is established with a direct current of 390 amperes and a power of $56.7 \mathrm{kw}$. The remainder of the supply capacity is such that a 20-kgauss center field can be established for the theoretical acceleration of deuterons to $35 \mathrm{Mev}$ at a radius of 27 inches. Figure 4 shows the magnetization curve.

The normal operating center field is 14.9 kgauss with a $2.6 \%$ drop off at the exit radius of $25 \frac{3}{4}$ inches (see Fig. 5). The field index $\mathrm{n}$ at this exit radius is approximately 0.3. Field stabilization of 1 part in 20,000 is obtained by nuclear magnetic resonance techniques. 


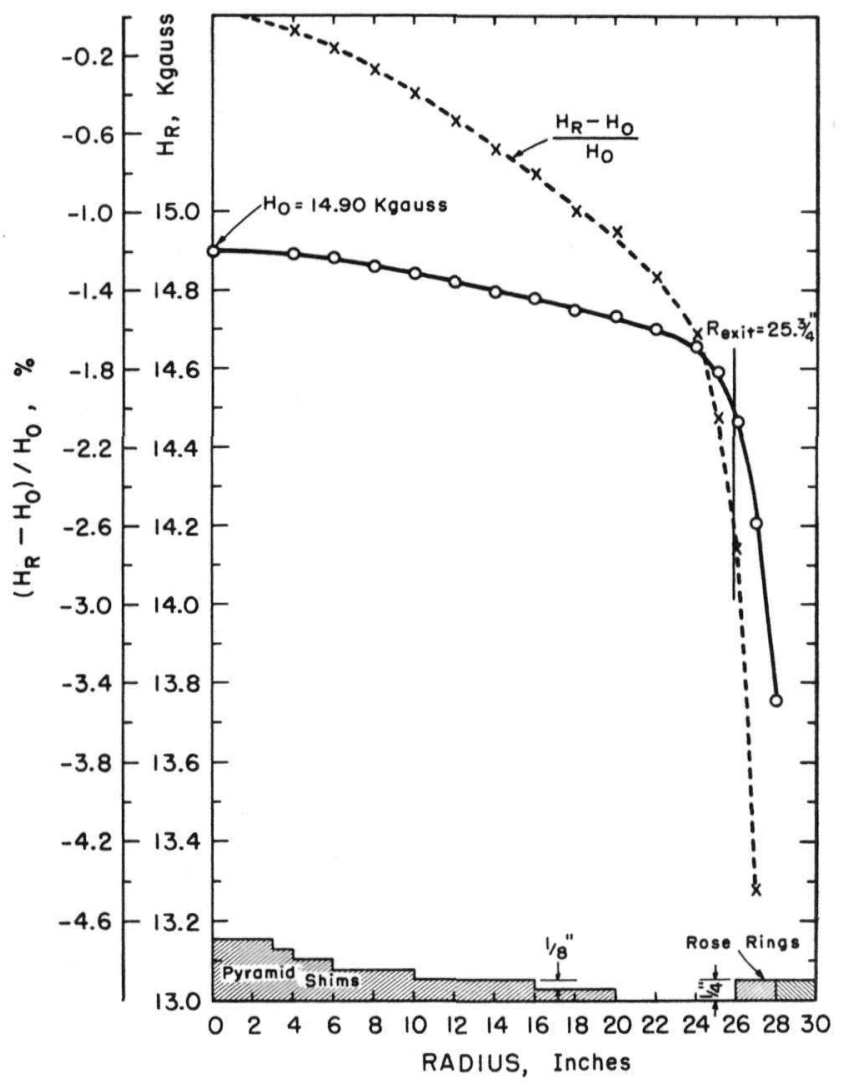

Fig. 5 Field contour of the 60-inch cyclotron magnet.

Azimuthal field measurements showed that for all radii out to 26 inches, the maximum flux variation is less than 1 part in 3000 . The medium plane of the magnetic field is within 0.030 of an inch of the geometrical median plane.

$\operatorname{Arc}$

The ion source is a conventional DC-type hooded arc, consisting of a $1 / 8$-inch tantalum hairpin filament and a graphite chimney, 5/16 of an inch in diameter with an aperture size of $3 / 32 \times 7 / 32$ of an inch in length. The filament is heated by a $220 \mathrm{kc} / \mathrm{sec}, 5-\mathrm{kw}$ transmitter, and a typical deuteron arc is maintained at 50 to 120 volts DC, 6 to 8 amperes drain, with a gas flow rate of about $0.1 \mathrm{cc} / \mathrm{min}$. Filament and chimney life have averaged 25 to 30 hours, although helium ion operation reduces the life to about 10 to 15 hours. The mechanics of the system are such that a filament or chimney change, or both, can be accomplished and the machine back into operation within a fifteen-minute period.

Ion extraction from the chimney is accomplished by block-type water-cooled copper feelers. The feelers are 5 inches in length with a 1 -inch vertical gap. 
The arc system motion is confined to (a) manual or remote positioning of the filament with respect to the base aperture of the chimney (b) remote positioning of the chimney in a plane parallel or perpendicular to the dee lips, and (c) manual chimney rotation for alignment with the magnet field.

Radiofrequency System

The energy imparted to the extracted ions is obtained from the $\mathrm{rf}$ system, consisting of the dees and stems, dee shielding, shorting bar, oscillator-power amplifier and the DC power supply. The rf electrodes constitute a conventional twin dee unbiased system with both dee stems mounted in a common evacuated tank (see Figs. 1 and 2).

The dees are 4 inches in height with a $2 \frac{3}{4}$-inch internal depth and a $2 \frac{1}{2}$-inch vertical entrance gap. Dee heads have a 12 -inch parallel section at the center with an edge flareback of approximately $10^{\circ}$. The vertical spacing between the OFHC copper liners of the acceleration chamber is 9 inches, leaving $2 \frac{1}{2}$ inches from each dee surface to ground. The effective capacitance of each dee to ground is about $280 \mu \mu \mathrm{f}$ and is dependent upon dee and trimmer plate positions. For each dee, the trimmer condenser plates provide approximately a $25-\mu \mu \mathrm{f}$ variation in capacitance. The dees and stems are of 1/4-inch thick OFHC copper fabricated from a 12 -inch $O D, 1 / 4$-inch thick tube. Such fabrication resulted in a dee and stem of continuous copper except for the top and bottom lip area of the dee. For this region, OFHC copper was copper welded to the main assembly to give the required shape. Both dees are extensively water cooled with all copper tubing continuously Sil-fos soldered to the interior surfaces. Each dee and stem is mounted on a nickel-plated carbon steel tube that extends from well inside the dee stem to the outside of the VTO box and passes through a stainless steel bellows which acts as a flexible vacuum seal. This tube is supported in a gimbal inside the VTO box, permitting remote control of the dee position in both the horizontal and vertical planes, by means of motor drives located outside of the vacuum.

The shielding of the dee system is accomplished by the OFHC copper of the vacuum chamber, a description of which has been given.

The electrical length of the dees is established by the position of the shorting bar. Figure 2 is a view of the shorting bar in position with respect to the dees and the obround. This unit, extensively water cooled, consists of several sections of OFHC copper plate supported by a copper frame. Contact to the dee stems is obtained by the use of Mallory-3 metal fingers silver soldered to their respective plates and held against the stem by a main and several auxiliary tension bands (see Fig. 6). Connection with the ground shield is obtained by a sector technique, that is, by numerous 
finger groups individually adjusted to press the fingers against the envelope. Approximately 125 inches of the envelope are in contact with the fingers. This short has operated quite satisfactorily, carrying a calculated current of 2000 RMS dee stem amperes without any serious indication of heating.

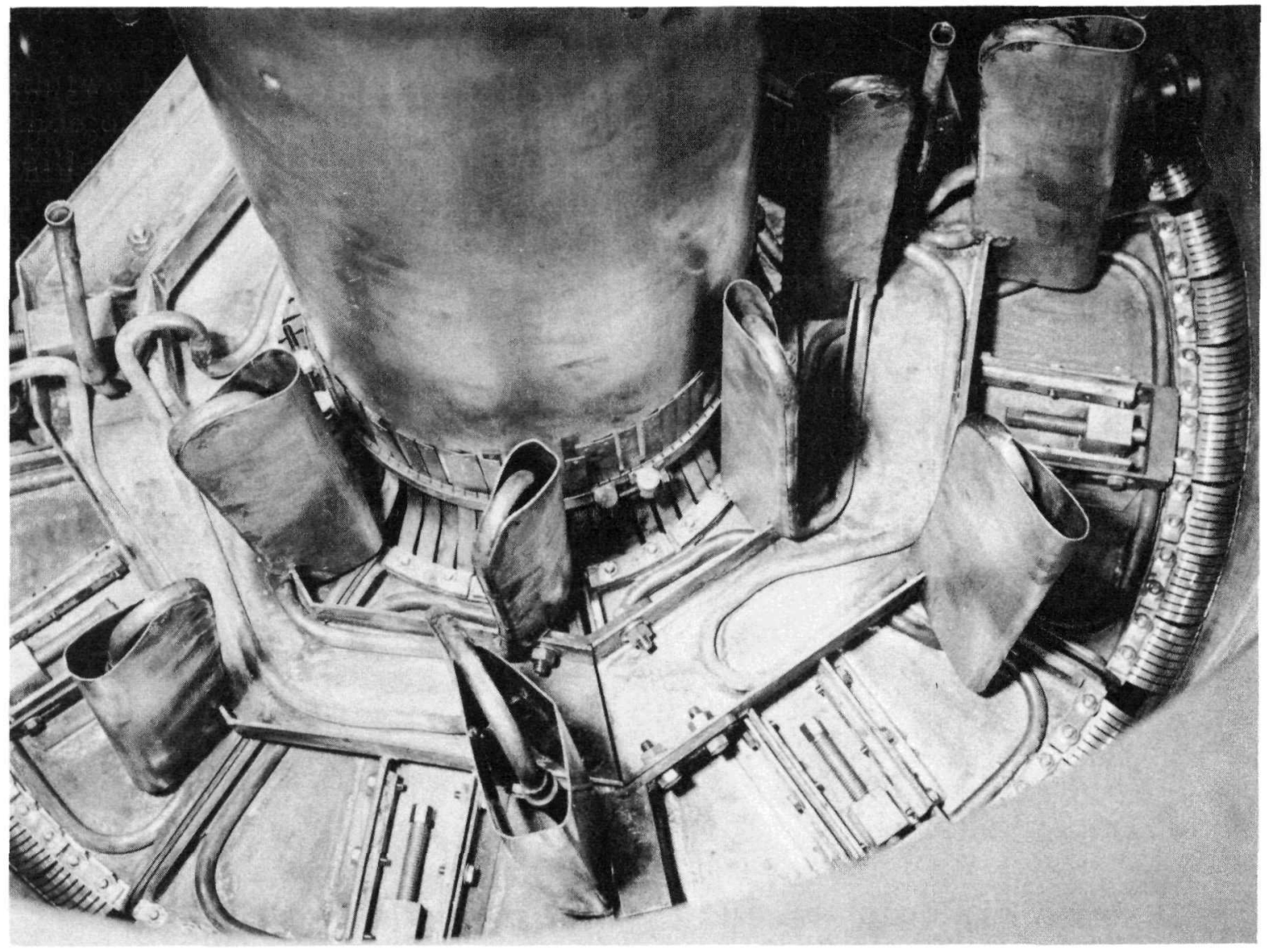

Fig. 6 Radiofrequency shorting bars and dee stem; rear view.

The energy to the dees is transferred from the oscillatoramplifier system (Fig. 7) by inductive coupling. The self-excited oscillator consists of a rf grounded cathode, tuned plate, untuned grid circuit with two Machlett type ML-356 tubes operating in push-pull. The capacitance of the plate circuit is adjustable from the control console. The oscillator output inductively couples to the cathode circuit of a grounded grid amplifier which functions with two ML-5681 tubes in push-pull. The amplifier plate leads conductively couple to the amplifier-dee system coupling loop. The coupling loop is of one turn, $6 \times 10 \frac{1}{4}$ inches, with the 6 -inch side parallel to the dee stems and the center of the loop grounded.

Operating dee to dee voltages of about $310 \mathrm{kv}$ peak are attainable with normal operating values being about $260 \mathrm{kv}$. Typical operating data are: a resonant frequency of $11.2 \mathrm{Mc} / \mathrm{sec}, 240$ to $260 \mathrm{kv}$ dee-dee, about $5 \mathrm{kv}$ plate voltage, 100 to $120-\mathrm{kw}$ plate power input to the oscillatoramplifier, and $200 \mu \mathrm{amp}$ of deflected deuterons. 

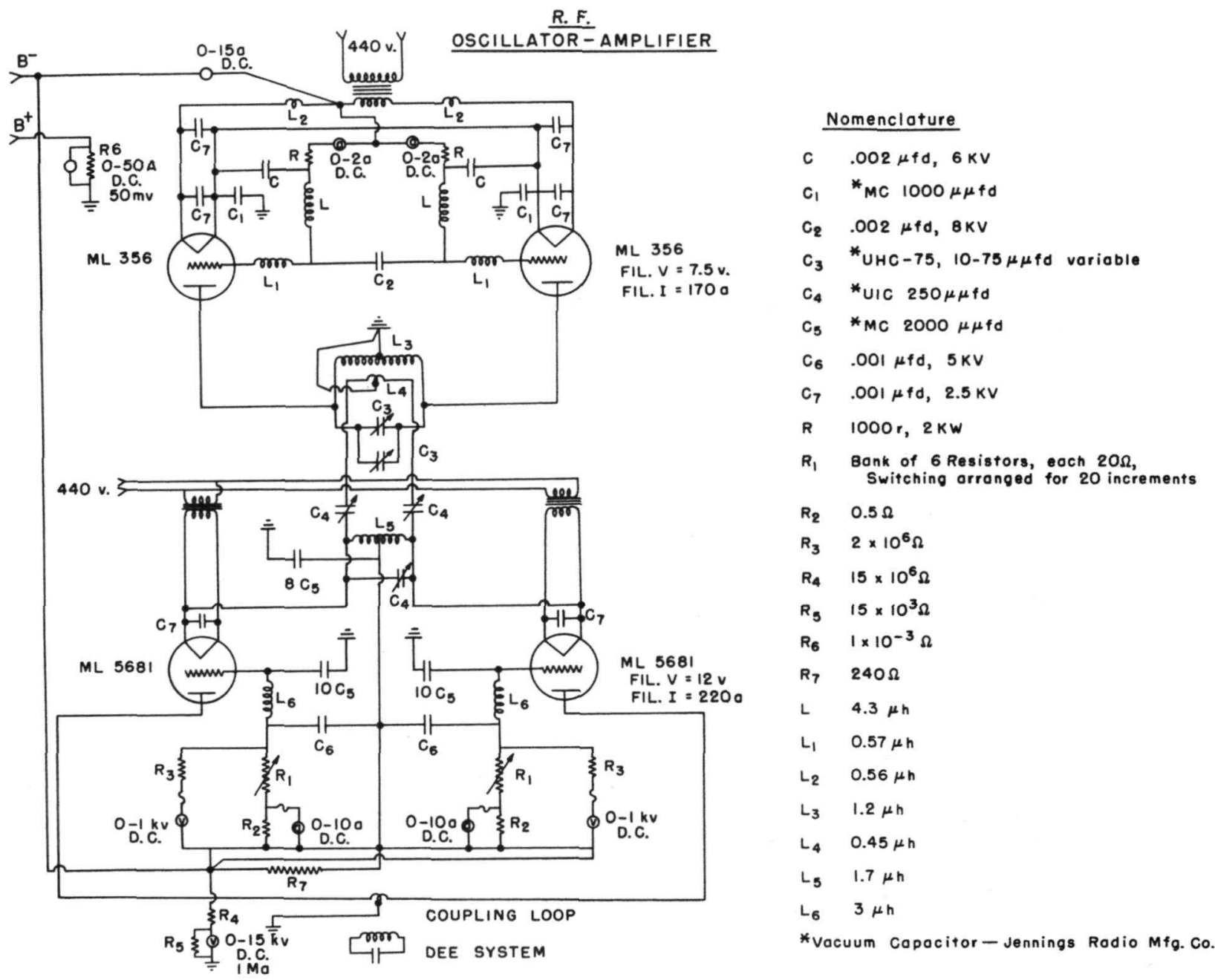

Fig. 7 Radiofrequency oscillator-amplifier schematic

For this type of operation, the ratio of loaded to unloaded $Q$ is 0.57 , with the $Q$ of the unloaded circuit being about 10,000 . The combined efficiency of the oscillator-amplifier system is about $47 \%$.

The energy to the rf system is supplied by a $10-\mathrm{kv}, 400-\mathrm{kw}$ DC power supply consisting of a 6-phase rectifier and transformer using 857B-type tubes, a constant current network, a remotely controlled induction regulator with an $83.5 \%$ buck-boost feature, and a 3 -phase, remotely operated 2400 -volt line contactor.

Measurement of dee voltage is obtained by probes located at the top and bottom of each dee and capacitively coupled to the dee. In turn, each set of dee probes are directly coupled to a rectifier circuit employing a 1 N34 crystal. Opposite crystal polarities are used for the top and bottom probes with the rectified output applied to a DC voltmeter giving the peak 
dee kilovoltage to ground. To the first approximation, the measured voltage is independent of dee position. This circuitry has functioned quite satisfactorily without any noticeable deleterious effects from the radiation field.

Resonance tuning of the cyclotron is accomplished by varying the radiofrequency with the DC magnet field constant. The frequency is remotely varied by positioning the dee trimmer condenser plates, thereby changing the capacitance of the dee system and the resonant frequency of the rf system. Compensating tuning of the oscillator is accomplished by a remotely controlled, variable vacuum capacitor in the plate tank circuit. The remote adjustable tuning span of the oscillator is $1 \mathrm{Mc}$, in the $11-\mathrm{Mc} / \mathrm{sec}$ region. The frequency of oscillation is controlled to one part in 10,000 by comparing the oscillator frequency against a standard frequency generator, with the resulting error signal introduced into a detector to establish phase. The error signal output is used to position the dee trimmer plates, altering the dee system capacitance and correcting the $\delta$ f change.

\section{Deflector}

The deflector system is a means of diverting the accelerated ions

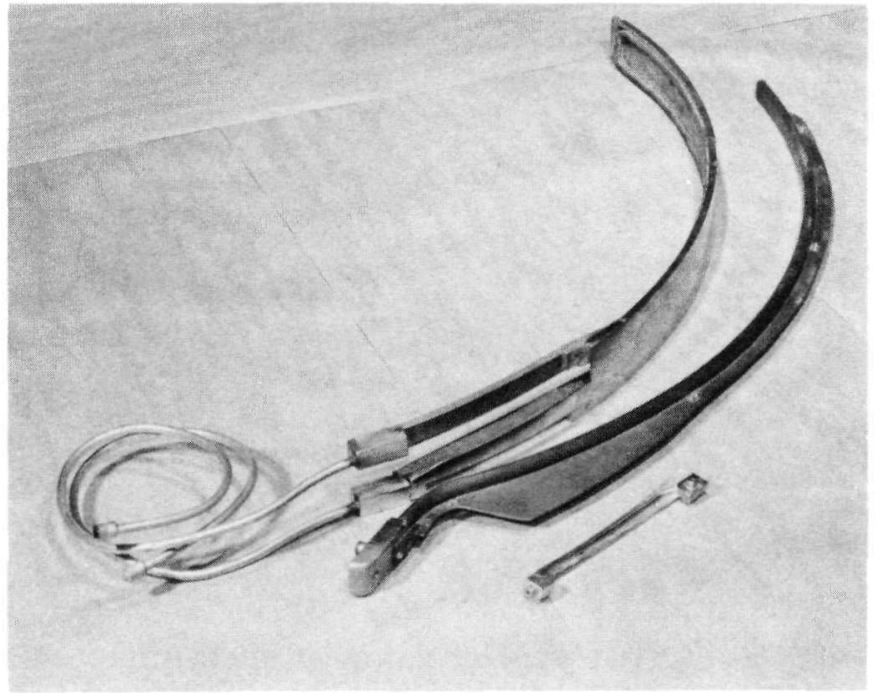

Fig. 8 Deflector system showing the septum, deflector and the top half of the beam splitter. from their normal orbits of rotation. The Argonne system is a customary internal unit, located in the dee opposite to the ion extraction dee, and consists of two curved OFHC copper planes between which a DC electrostatic field is established to direct the accelerated particles to the exterior of the machine. The two curved planes (Fig. 8) are customarily referred to as the septum and deflector.

The septum is mounted between the deflector and the cyclotron center. The septum unit consists of the septum proper and the entrance por-

tion, called the beam splitter. The septum proper is constructed of copper, $3 \frac{1}{4}$ inches wide, $3 / 8$ inches thick, and is water cooled. The beam splitter, 10 inches long, consists of two 0.062 -inch thick copper plates with a cooling water line hard soldered to each plate. The plates are so shaped to form a horizontal $\mathrm{V}$ notch centered on the median plane. The notch extends the 
length of the splitter and is about one inch wide at the splitter entrance, tapering to about $1 / 16$ inch at the other end. Both splitter sections are readily removable and are so constructed that they plug into the cooling water lines. This type of unit has been in service for many thousands of hours of operation with negligible maintenance.

The success of this beam splitter was only attained after numerous unsuccessful tests of other units. Rapid destruction by heating occurred with the earlier designs of tungsten, carbon or copper, either uncooled or water cooled. The satisfactory operation of the present design is primarily dependent upon the extensive $\mathrm{V}$ notch.

The deflector is a hollow copper tube, obround in section, $1 \frac{1}{4}$ inches high, 5/8 inch wide, with a wall thickness of 0.049 inch, and is closed at the end adjacent to the exit of the deflector channel. Cooling is obtained by passing water down a tube positioned in the center of the deflector with the return water forming a cooling sheet on the internal periphery of the unit. The deflector is connected to the deflector stem by means of an "O" ring plug-in technique. Access to the deflector is obtained by removing the dee trimmer box and unbolting a section of the dee side, thereby enabling one to remove or service the unit without pulling the dees from the acceleration chamber. The deflector stem is of type 304 stainless steel, coaxially extending back into the dee stem where it is supported at its midpoint by a porcelain insulator. The deflector stem leaves the vacuum chamber through a stand-off insulator and metal bellows.

The deflector and septum are each approximately forty-seven inches in length, and their shape is that of a circular arc with a radius of curvature of 30 inches. The entrance to the deflector system, nominal $1 / 4$-inch width, is located approximately $50^{\circ} \mathrm{CCW}^{*}$ from the center line of the dee system and is at a radius of about $25 \frac{3}{4}$ inches; the exit, $5 / 8$ inch wide, is at a radius of 30.5 inches, $145^{\circ} \mathrm{CCW}$. With the application of a negative $75-\mathrm{kv}$ DC potential to the deflector, the orbital radius of the particles increases $17.5 \%$, thereby enabling the particle to escape to the external target area.

Motions of the deflector system are simple but effective. Both ends of the septum unit are so mounted that they can be manually moved towards or away from the physical center of the acceleration chamber. The exit position can be externally adjusted, but the entrance position can only be changed by opening the acceleration chamber. These position changes are infrequently required and the septum orientation has not been changed in the last four years of operation.

*As viewed by looking down on the acceleration chamber. 
The deflector has four provided adjustments: positioning with respect to the entrance radius; vertical rotation; vertical plane motion; and in and out motion with respect to the septum. The latter varies the gap of the deflector system and is the only motion controlled from the console. Similar to the septum unit, once the deflector position is optimized further adjustments are very infrequent.

The deflector efficiency is best expressed by considering the acceptance efficiency, that is, the deflected beam divided by the circulating beam at the exit radius. Efficiencies of 25 to 40 per cent are nominal and will vary depending upon operation parameters.

The deflector power supply is a full wave voltage doubler capable of an output of $150 \mathrm{kv} \mathrm{DC}$ at 50 -milliamp with less than $1 \%$ ripple. Normal operation is $75 \mathrm{kv}$ with a 3.5 -milliamp drain.

\section{$\underline{\text { Control }}$}

The control system voltage is 120 volts, with wiring and component coding following a combination of the zoning and system technique. For example, the relay racks in a given area are coded with a zone number, the components in the racks segregated by system, and then individual components and wiring terminals number-coded.

All control wiring, a total of $112-40$ conductor cables, is carried to one central location referred to as the intermediate distribution frame, consisting of 110 telephone-type connection blocks of 120 terminals each. At this location, cross connections are made which minimize the complexity of the wiring in regard to trouble shooting, wiring changes, and records.

\section{OPERATION AND BEAM CHARACTERISTICS}

Typical deuteron operating data are: a resonant freqeuncy of $11.2 \mathrm{Mc} / \mathrm{sec}, 240$ to $260 \mathrm{kv}$ peak dee to dee; $75-\mathrm{kv}$ DC deflector potential; and $200 \mu \mathrm{amp}$ of deflected beam. The tuning or optimizing of the machine is accomplished by the variation of the oscillator frequency with the DC magnet field held constant. The remote adjustable tuning span of the rf system is $1 \mathrm{Mc}$ in the $1 \mathrm{l}-\mathrm{Mc} / \mathrm{sec}$ region, thereby permittting the resonance tuning of single-charged molecular hydrogen, deuterons, or helium ions. 
The efficiency of acceleration can be considered as the ratio of beam power at the exit radius to the DC power input to the rf system. This value is about $10 \%$ for $120 \mu \mathrm{amp}$ of deflected deuterons, increasing to $15 \%$ for a $200 \mu \mathrm{amp}$ beam. About $30 \%$ of the internal beam at the exit radius is extracted from the acceleration chamber. Acceleration threshold voltages have been determined as $176 \mathrm{kv}$ dee to dee, as compared to the calculated value of $183 \mathrm{kv}$. (1)

Beam characteristics are a direct measure of machine performance and its usefulness as a research tool. In general, the beam can be characterized by considering beam intensity and distribution, energy and homogeneity, and the constancy of both beam intensity and energy. Figure 9 is a typical intensity record of the deflected deuteron beam. This irradiation was 8.7 hours in length with an average current of $200 \mu \mathrm{amp}$; the current variation excluding gas bursts and deflection dips was no greater than $\pm 10 \mu \mathrm{amp}$. Experience has indicated that nominal deflected beams are: $200 \mu \mathrm{amp}$ of $\mathrm{D}^{+} ; 100 \mu \mathrm{amp}$ of $\mathrm{H}_{\mathrm{e}}{ }^{++}$; and $100 \mu \mathrm{amp}$ of $\mathrm{H}_{2}{ }^{+}$. Deflected beam currents have exceeded these values and for sustained operating periods measured beams of $330 \mu \mathrm{amp}$ of deuterons and $170 \mu \mathrm{amp}$ of helium ions have been obtained.

Figure 10, a radioautograph of an irradiated copper target, is representative of the contour of the deflected beam at the first external target port. The vertical and horizontal profiles of this beam as obtained by a densitometer trace of the radioautograph are given by Figs. 11 and 12, respectively. A series of these profiles have been made for numerous horizontal and vertical positions. These data as plotted in Fig. 13 give an intensity contour map of the deflected deuteron beam.

The energy of the deflected deuteron beam has been established by both calorimetric and absorber techniques. The calorimetric measurement established an average value for the over-all beam energy of 21.3 Mev. An absorber technique, consisting of an aluminum wedge and lithium fluoride crystal detectors to determine particle cut-off, established a maximum beam energy of $21.6 \mathrm{Mev}$ with an energy spread of about $0.2 \mathrm{Mev}$ for the entire beam. For present operating parameters, a standard aluminum absorption analysis of a $1 / 8$-inch diameter beam segment established the mean range energy as $21.6 \pm 0.1 \mathrm{Mev}$. The straggling obtained by such a technique was $1.6 \%$, as compared to the theoretical aluminum absorber straggling of $1.1 \%$. It is this portion of the beam which has been used for nuclear activation and radiation chemistry studies. These programs have shown that the variation in beam energy is $30 \mathrm{kev}$ or less for many hours of operation. Recent measurements with ionization chamber techniques $(2)$ indicate that the beam energy constancy is $\pm 10 \mathrm{kev}$ or less for many days of operation. This includes complete machine shut-down at days end and start-up about 8 hours later. 

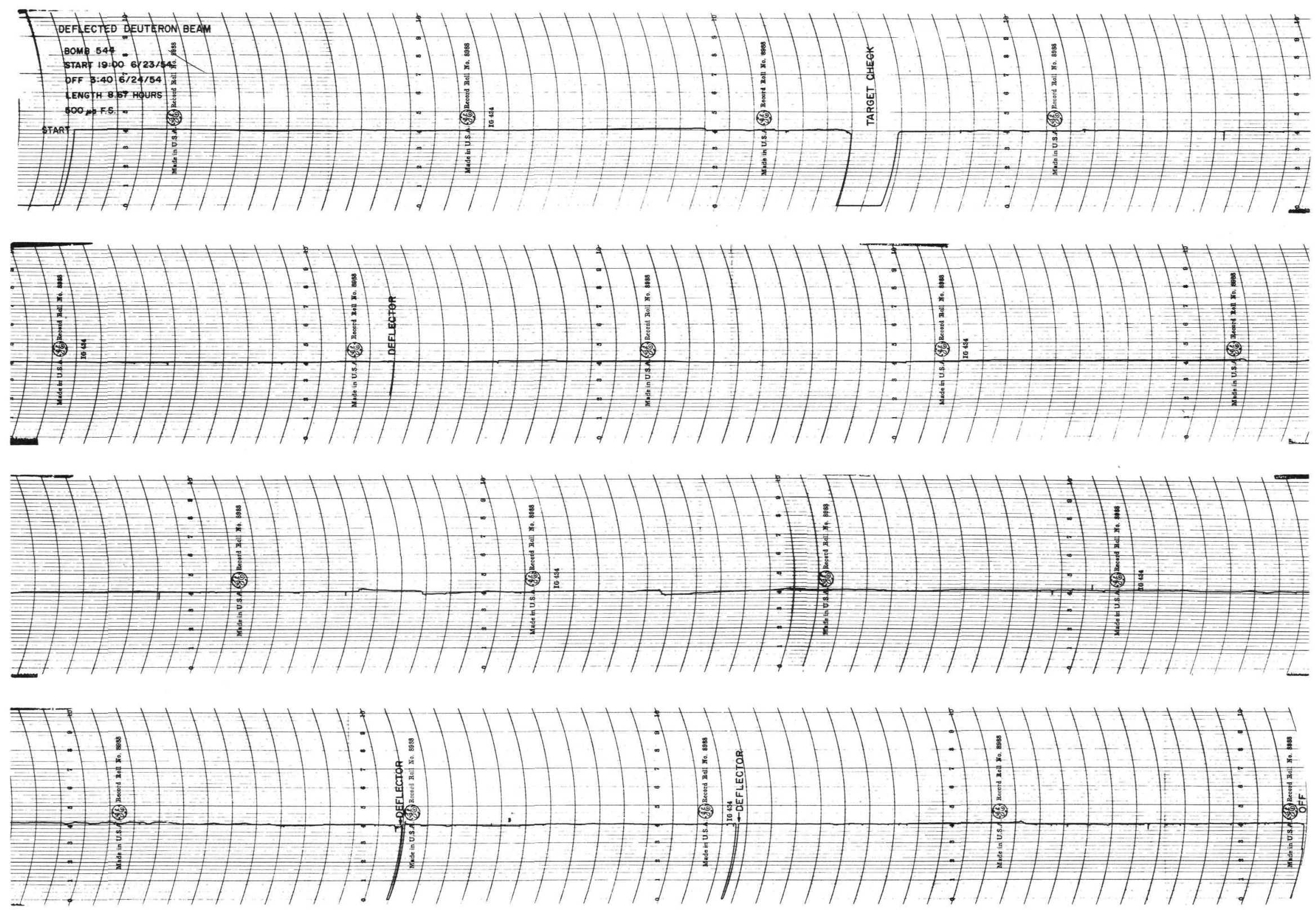

Fig. 9 Intensity record for a deflector deuteron beam irradiation. 


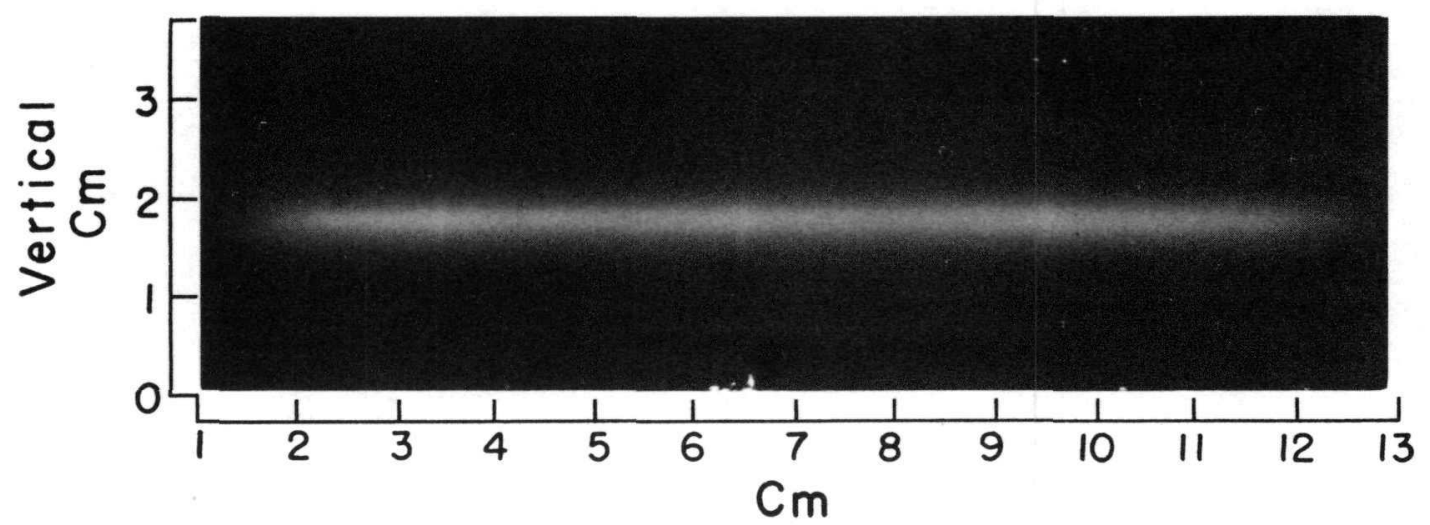

Horizontal

Fig. 10 Cross section of a deflected deuteron beam.

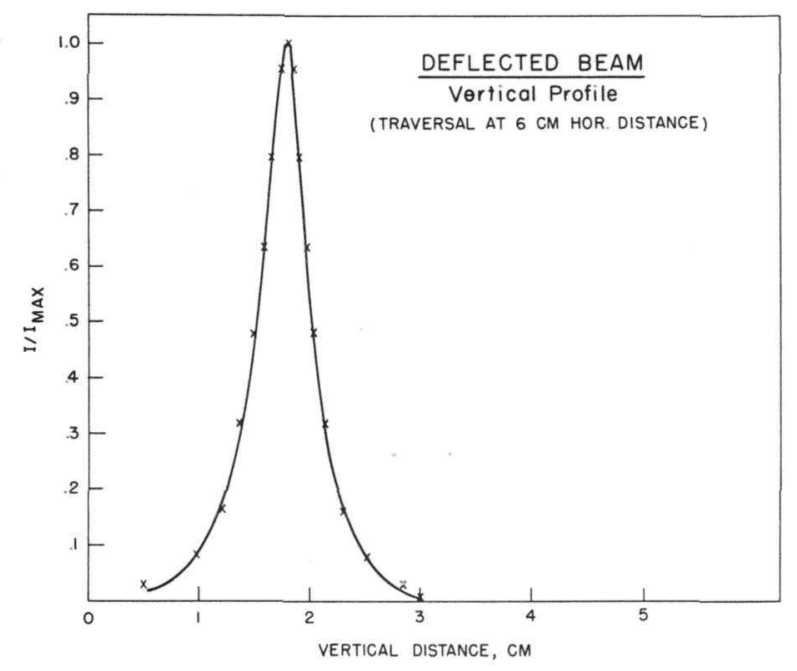

Fig. 11

Vertical profile of the deflected deuteron beam cross section given in Fig. 9.

Fig. 12

Horizontal profile of the deflected deuteron beam cross section given in Fig. 9.

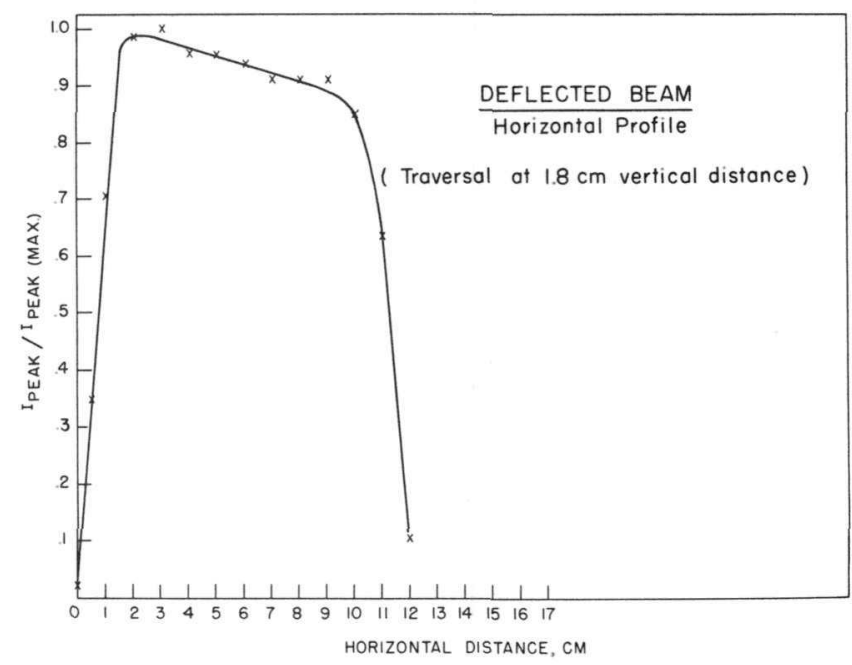




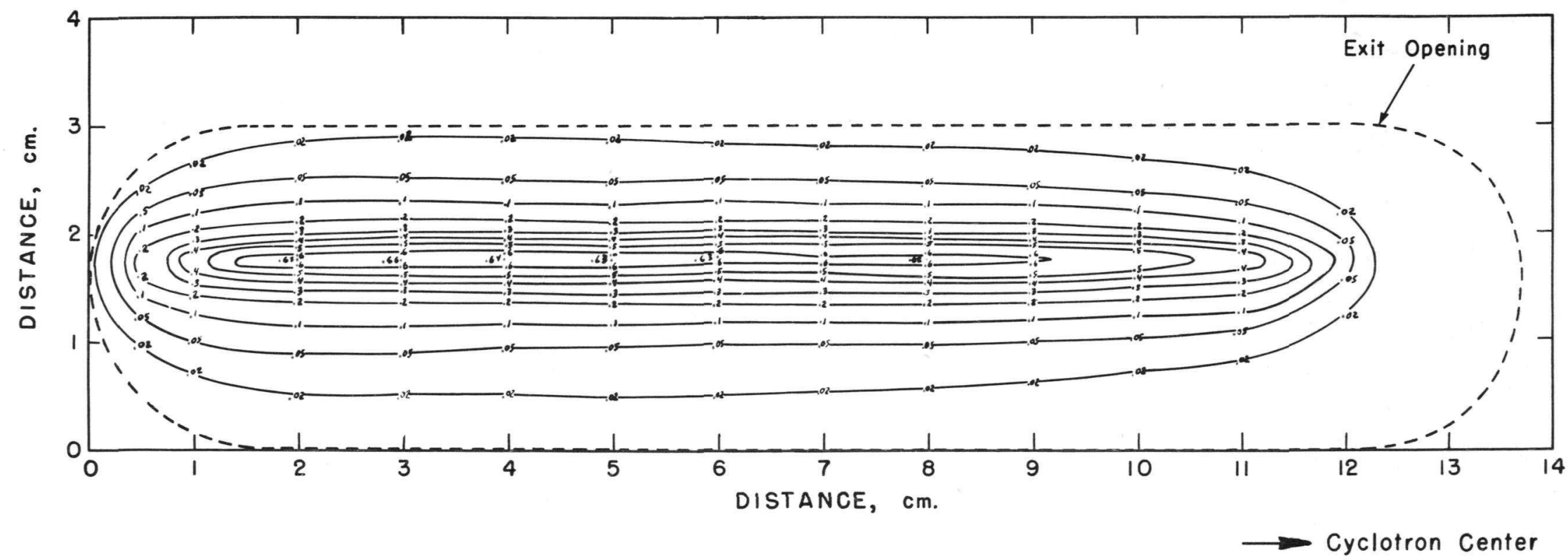

Fig. 13 Intensity contour map of the deflected deuteron beam given in Fig. 9. 
The dependence of the beam intensity and resolution on oscillator frequency is illustrated by Fig. 14.

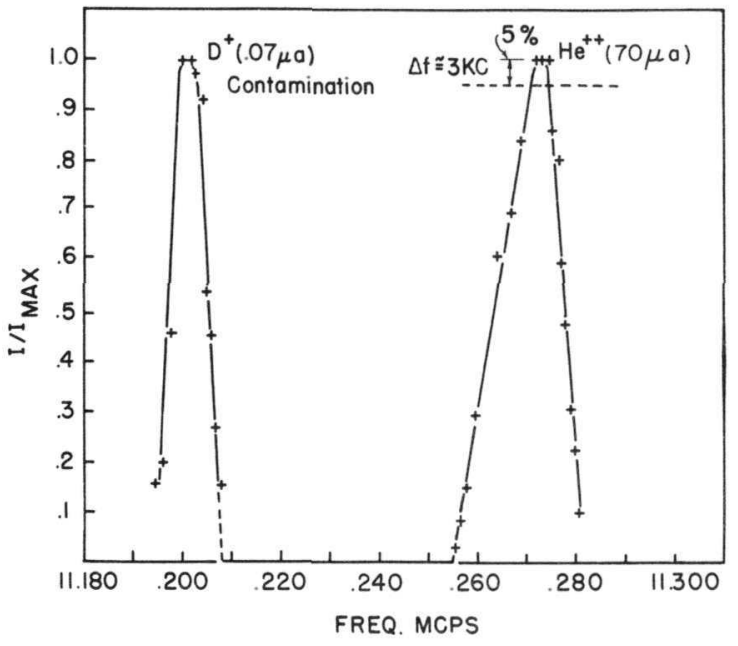

Fig. 14 Resolution of deflected $\mathrm{He}^{++}$and $\mathrm{D}^{+}$beams .
From these data, it is seen that for $5 \%$ current stability the oscillator frequency and magnetic field must have a combined stability of at least one part in 3000 . It is to be noted that the two resonant peaks have a frequency ratio of $f_{\alpha} / f_{d}=1.0064$, the approximate theoretical mass-charge ratio of the two ions.

The diversity of machine operation has been increased by an external strong focusing system (see Figs. 15 and 16). A maximum of $20 \%$ of the total deflected beam has been accepted and focused by this system. The cross section of the accepted beam is about

$5 \mathrm{~cm}$ horizontally and $2 \mathrm{~cm}$ vertically. The horizontal particle divergence is about 2 degrees from inner to outer edge, and the vertical divergence is about 0.2 degree from top to bottom. Using one magnet set, the beam can be readily focused into an area of $0.1 \mathrm{~cm}^{2}$, i.e., a particle density of $400 \mu \mathrm{amp} / \mathrm{cm}^{2}$ for a total deflected deuteron beam of $200 \mu \mathrm{amp}$. If the two quadrupole sets are close coupled, focal spots of $0.02 \mathrm{~cm}^{2}$ are obtainable. For a total deflected helium ion current of $60 \mu \mathrm{amp}, 6$ to $8 \mu \mathrm{amp}$ can be consistently focused through an aperture of $1 \times 2-m m$ cross section.

This focusing system also enables one to obtain about 12 to $15 \%$ of the total deflected beam in the experimental tunnel, about 30 feet from the cyclotron. The 60-inch nuclear scattering chamber is located in this area, and deuteron currents of $1 \mu \mathrm{amp}(70 \mu \mathrm{amp}$ total deflected) have been successfully focused into the chamber through a collimating system consisting of two $3-\mathrm{mm}$ diameter apertures, spaced one meter apart.

The external beam focusing system has been recently expanded to increase machine efficiency, flexibility, and experimental endeavor. The new switching magnet provides a total \pm 25 -degree beam orientation about the zero angle beam. Two additional beam ports have been installed in the experimental tunnel for a total of three irradiation stations in this area. The physical layout of the system is given in Fig. 15.

A "squeeze" coil magnet has been designed and will be positioned as shown in Fig. 15. It is calculated that the unit will increase the particle acceptance of the strong focusing system to about $50 \%$ of the total deflected beam. 


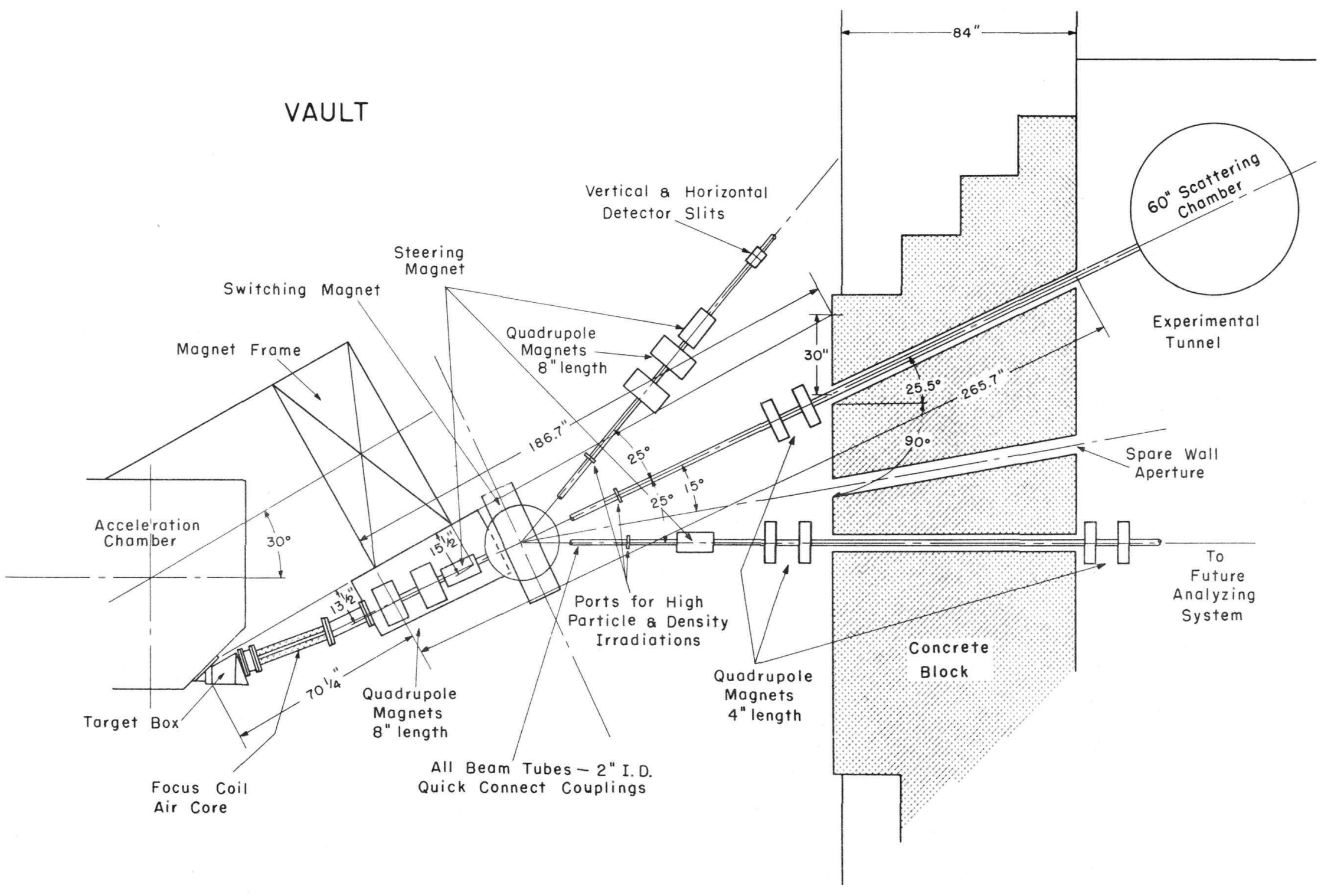

Fig. 15 Focusing system schematic. 


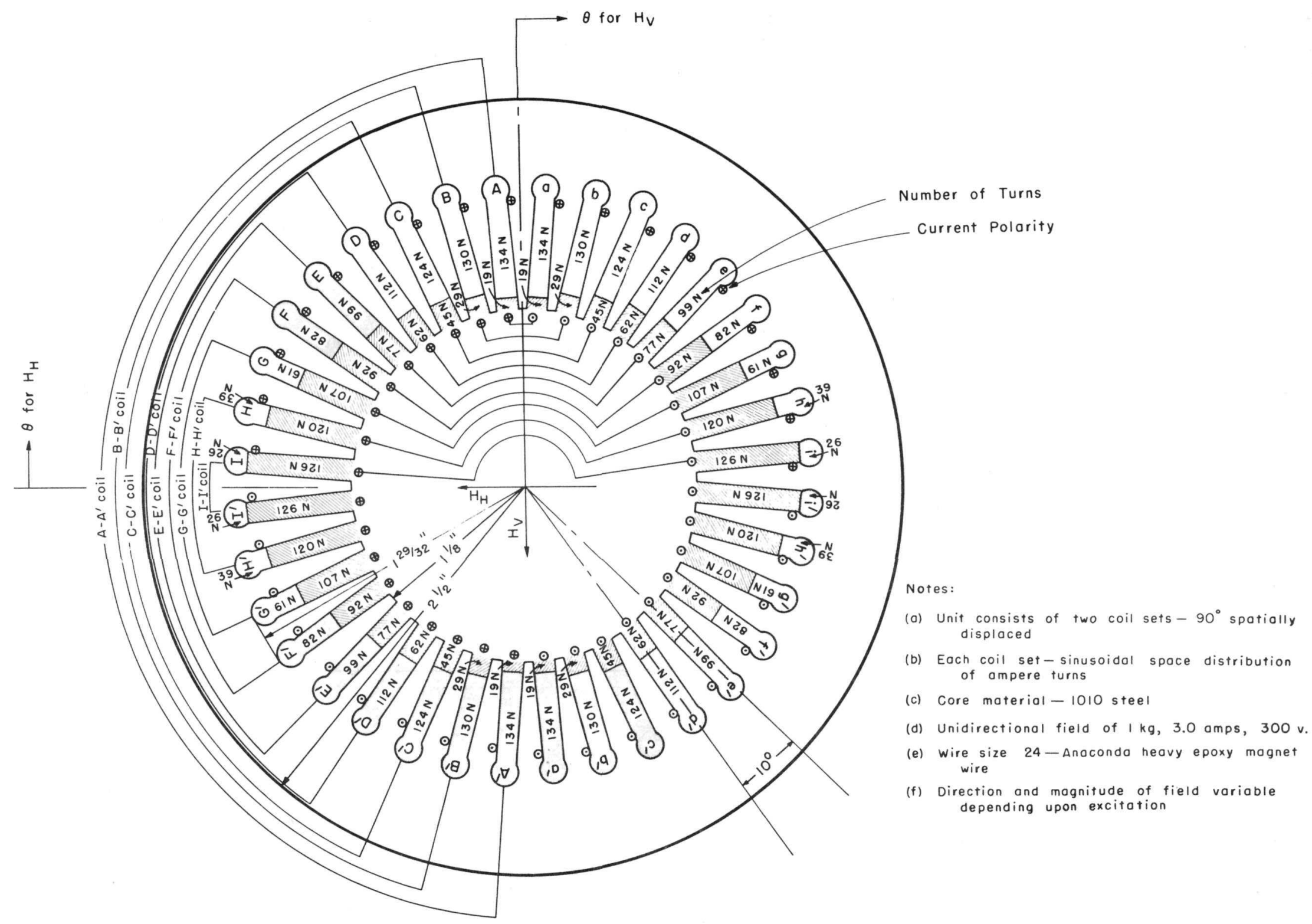

Fig. 16 Steering magnet - cross section of core. 
An energy degradation system, a foil absorber remotely controlled, is being installed with the strong focusing quadrupoles to degrade the energy of the primary beam by a factor of 4 . Energy-bunching techniques are under consideration to reduce the energy straggling to a few tenths of one per cent, with particle number remaining constant.

A major item still to be designed and installed is an energy analyzer with a resolution of about $0.05 \%$ or better.

Focused beam channeling or positioning is accomplished by a cylindrical-type steering magnet that provides both uniform vertical and horizontal field components. The aperture of the unit is $1 \frac{7}{8}$ inches in diameter, with the beam entering on the axis of the system. Deflection fields are established by excitation coils located in the radial type winding slots of the core.

The plane of each coil is perpendicular to the designed field direction, and the distribution of turns varies as the sine of the angle as referenced to a line through the core center and parallel to the designed magnetic field(3) (Fig. 17). The horizontal and vertical magnetic field components are provided by two coil sets spatially displaced by 90 degrees. Basically, the existing design consists of a cylindrical core of iron, 2 inches ID, 5 inches OD, 9 inches long with the windings placed in radial type slots located 10 degrees apart. For a DC power input of 300 volts and 3 amperes, the established unidirectional field is 1 kilogauss. Measurements of the fields indicate a homogeneity better than $0.2 \%$, and deflected beams are free of noticeable distortion effects. In addition to beam positioning, this unit can provide a magnetic sweep field to cycle the beam and obtain particle homogeneity of $0.5 \%$ or better for target irradiations.

The major proportion of the irradiations performed with the cyclotron are with a deflected beam; however, internal probe work is possible and is performed when feasible. External beam work has been predicated by the nominal deflected beam of $200 \mu \mathrm{amp}$ and the high current densities obtainable by use of the focusing system. The use of a deflected beam simplifies target design and permits the instrumentation to precisely characterize the irradiating beam, permitting a diversified experimental endeavor.

A broad energy spectrum of neutrons is also available for irradiations. For deuterons on beryllium, the forward flux at the surface of a thick target is $2 \times 10^{9} \mathrm{n} / \mathrm{sec} / \mathrm{cm}^{2} / \mu$ amp with a particle maximum at $7.5 \mathrm{Mev}$. (4) This flux value was measured by use of the $S^{32}(\mathrm{n}, \mathrm{p}) \mathrm{P}^{32}$ reaction, which has a threshold energy(5) of about $2 \mathrm{Mev}$. 
The use of the cyclotron is extremely diversified with the type of accelerated particle varying from day to day. At times, experimental demands have dictated the acceleration of deuterons, helium ions and molecular hydrogen ions in the same day. Currents and irradiation time requirements vary from $10^{-10}$ ampere for a few seconds to more than 200 microamperes for many hours. From January 1, 1957 through December 31, 1957, a total of 2857 irradiations were performed; the average "beam on" target time was $46 \%$ of the available operating hours and approached a sustained $60 \%$ in the last quarter of the year.

In summary, the stability of operating characteristics can be directly attributed to the following:

(a) Extensive water cooling with water temperature stability of $1^{\circ} \mathrm{F}$ or better.

(b) Vacuum System:

(1) Excellent mechanical construction;

(2) $3000 \mathrm{l} / \mathrm{sec}$ pumping speed;

(3) Extensive use of OFHC copper.

(c) Magnet System:

(1) Mechanical stability of magnet excitation coils;

(2) Field stability of 1 part in 20,000.

(d) Arc System:

Excellent stability of $\mathrm{H}_{2}^{+}, \mathrm{D}^{+}$, or $\mathrm{He}^{++}$production.

(e) Radiofrequency System:

(1) Extensive water cooling;

(2) One-piece fabrication of dee and stem from a 12 -inch OD, $1 / 4$-inch thick tube;

(3) Reserve power design of the oscillator-amplifier;

(4) Frequency stability of one part in 10,000;

(5) Resonance tuning accomplished by varying frequency, magnetic field held constant. 
(f) Deflector system:

(1) Sturdy construction and extensive water cooling;

(2) Acceptance efficiency of 25 to 40 per cent;

(3) Adjustable motions provided for the deflector and septum units.

\section{CYCLOTRON BUILDING}

$\underline{\text { Design }}$

To house the cyclotron and to provide for its proper and intensive utilization, it was necessary to design and construct a building having many special facilities. Building floor plans were dependent upon machine design, direction of particle rotation, and the contemplated experimental uses of the machine.

The Cyclotron Vault was designed around the major axis of the machine with the walls placed parallel to the axis to simplify building construction. The vault Dee Door was so located to permit the complete withdrawal of the mobile dee assembly to the Dee Repair and Dee Storage areas. The Machine Shop was located adjacent to these areas to facilitate possible machine repair.

The Experimental Tunnel location was governed by the position of the external beam, and the Hot Laboratory was positioned in close proximity to the target area to facilitate the handling of irradiations. The position of this laboratory determined the location of the chemistry laboratories and experimental areas. To have rapid vault access from the laboratories, the Personnel Vault Access Door was located adjacent to the Hot Laboratory. This door location positioned the Control Room so that the accelerator operators could readily enter and visually control the access to the vault.

Installation routes of electrical leads, vacuum lines, etc., to the cyclotron had to be direct, and, insofar as possible, all electrical and mechanical equipment had to be installed external to the vault for ease of routine maintenance and repair. In addition, it was considered essential to have direct access to the electrical and mechanical equipment from the control room. These requirements, coupled with the method of introducing leads to the vault without the use of floor trenches and the consideration of noise and vibration, led to the design of two equipment areas: an Electrical Equipment Room located on the first floor for non-rotating equipment, and a Mechanical Equipment Room located directly below on the Service Floor. 
The remaining areas of the building were located to effect the most economical utilization of space. The resulting floor plan is as shown in Figs. 17 and 18.

$\underline{\text { Vault }}$

The cyclotron vault is 40 feet by 50 feet, with the axis of the dee assembly parallel to the long dimension and coinciding with the center line of the room. The ceiling height is 28 feet, providing sufficient clearance for a 10 -ton precision hoist bridge crane. The vault walls are 7 feet

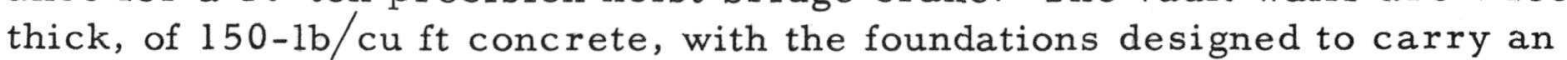
additional 3 feet of heavy $(300 \mathrm{lb} / \mathrm{cu} \mathrm{ft})$ concrete shielding. The roof consists of 4 feet of $150-1 b / c u f t$ concrete, with the structure designed to support an over-all thickness of 7 feet. The personnel door, weighing about 38 tons, can be closed in one minute and opened in 30 seconds. The 120 -ton Dee Door (Fig. 19) can be closed in about 5 minutes and opened in 1 minute.

Two viewing windows are provided: one in the Hot Laboratory to provide for observation of the target area and the internal volume of the acceleration chamber, and the other in the electrical equipment room for viewing of the diffusion pumps and the rf oscillator-amplifier. A window consists of two cells, each solution filled and $3 \frac{1}{2}$ feet thick. The cell on the vault side contains water and copper sulfate to eliminate bacterial growth. Zinc bromide in solution with a density of $2.50 \mathrm{gm} / \mathrm{cm}^{3}$, is the medium of the second cell. The indices of refraction for the water and the zinc bromide units are 1.33 and 1.56, respectively. The over-all luminous transmission for each window is about $25 \%$ for tungsten light. These windows have been completely free of trouble and have performed excellently in regard to shielding and optical properties.

All service leads to the vault are brought from the Mechanical Equipment Room through sleeves in the 7-foot thick wall. All sleeves are straight-through openings with diameters ranging from 2 to 12 inches. Since the radiation leakage through these sleeves is negligible, shielding material is not used to seal the openings. Fifty per cent spares were provided for future expansion. Todistribute the services in the vault feasibly, a pattern of floor slots was provided. Such an arrangement permits the connection of equipment without the "vine" effect.

The vault is air conditioned and is provided with $50 \%$ relative humidity control. The area is maintained at a negative pressure of 0.1 inch of water to minimize the leakage of contaminants. The vault air flow is $7050 \mathrm{cfm}$, providing a complete air change every 8 minutes. 


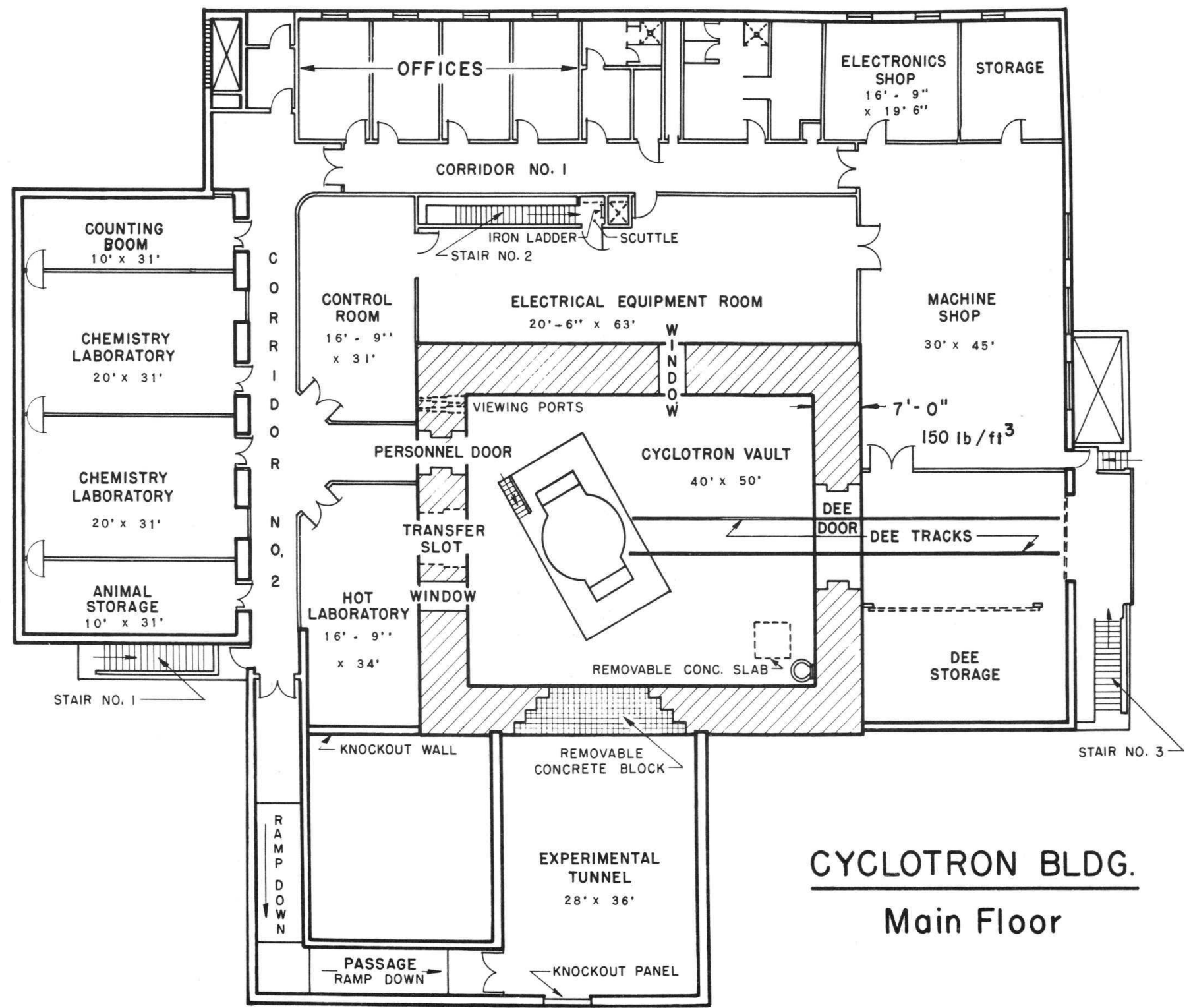

Fig. 17 Main floor plan of the cyclotron building. 


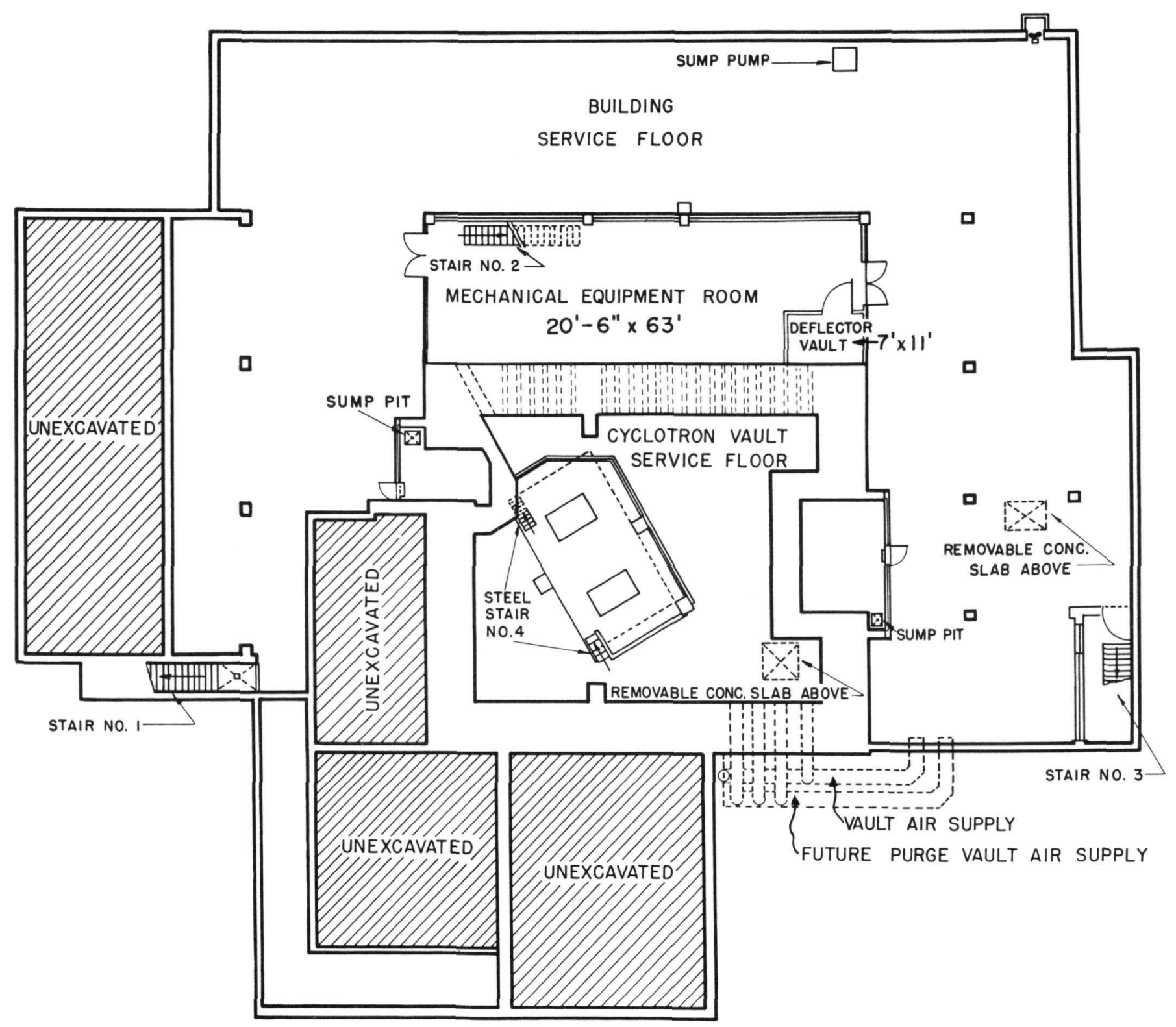

Fig. 18 Service floor plan of the cyclotron building. 


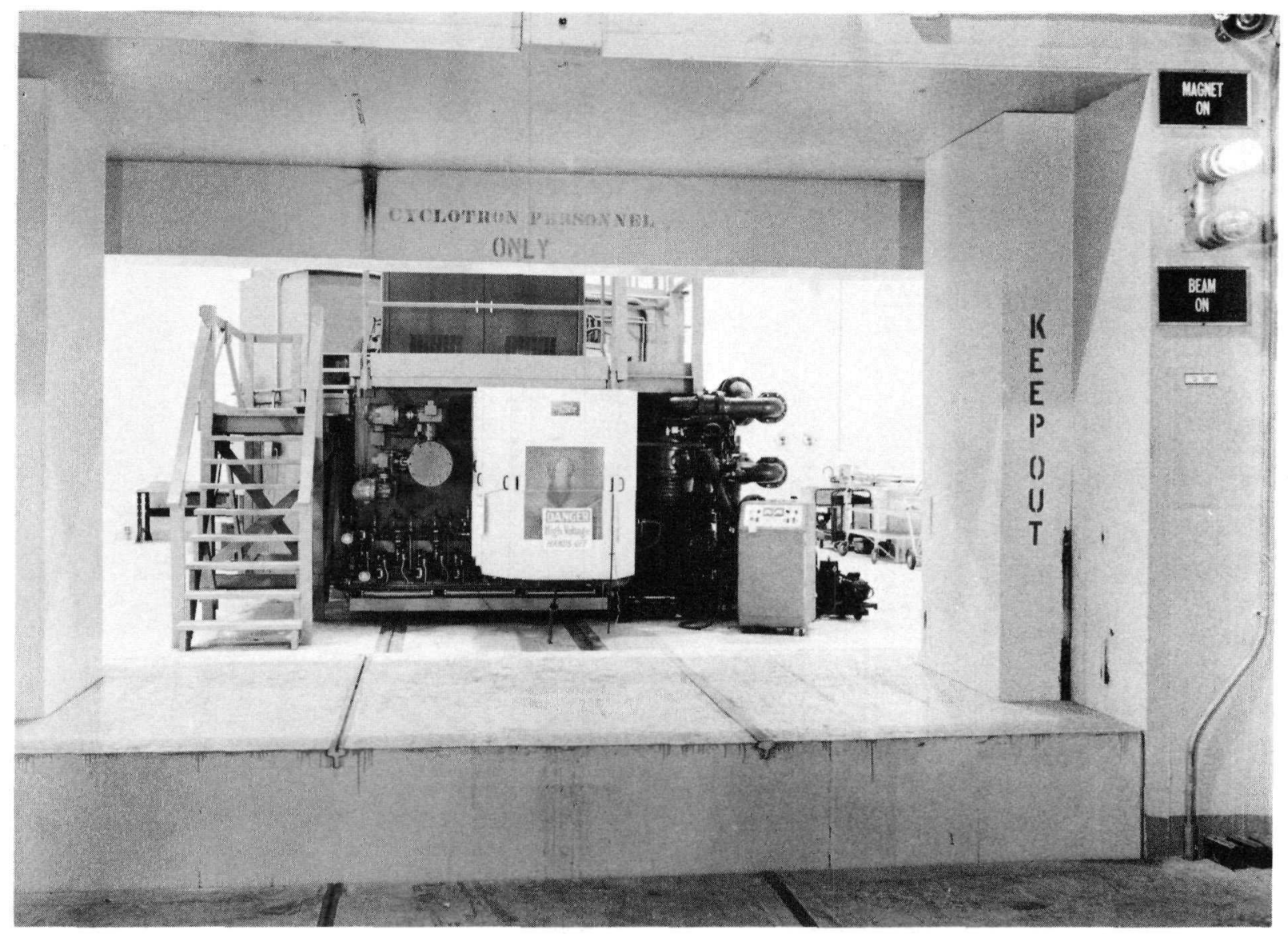

Fig. 19 Vault dee door in partially closed position.

\section{Control Room}

This room contains the control console, relay racks for cyclotron control circuitry, and experimental equipment for cyclotron irradiations. All equipment wiring is through floor slots to raceways located on the ceiling of the room below. The room is air conditioned for both temperature and humidity and is glass enclosed to permit operator control of vault access.

\section{Electrical Equipment Room}

This area houses the power supplies for the oscillator-amplifier and the ion source. It also contains all of the relays required for control and interlocking. Wiring to the equipment is through floor slots with raceways located on the ceiling of the room below. This room is not air conditioned, but is ventilated by filtered air. 
Mechanical Equipment Room

Here are located the mechanical vacuum pumps, cooling watercirculating system, magnet motor generator set, and an auxiliary air compressor.

Deflector Vault

The deflector vault contains the oil-immersed deflector voltage supply. For safety, this area has a two-hour fire rating and contains a $\mathrm{CO}_{2}$ fire-extinguishing system. This area is ventilated by filtered air.

Hot Laboratory

The Hot Laboratory contains one Senior and two Junior caves. The Junior caves have an inside working area of about $20 \times 48$ inches with a filtered air intake and exhaust. The shielding consists of 3 inches of steel with a 9-inch lime glass viewing window. Each unit contains two Model 7 master-slave manipulators.

The Senior cave has an inside working area of $6 \times 10$ feet with a filtered air intake and exhaust. The shielding consists of about 24 inches of ferrophosphorous concrete, having a density of $300 \mathrm{lb} / \mathrm{cu} \mathrm{ft}$, with two oil-immersed multiple-layer glass windows. Each window is $24 \frac{1}{2} \mathrm{x}$ $30 \frac{1}{2}$ inches in effective cross section and 29 inches thick. The target transfer slot, Fig. 17, is located in the cave to facilitate the transfer of hot targets from the cyclotron. Four Model 8 master-slave manipulators and a 1 -ton bridge crane are provided for material handling. Storage of radioactive materials is accomplished by 6 -inch diameter sleeves originally cast in the vault wall.

This room is provided with conditioned air and filtered exhaust.

Laboratories

There are four laboratories: two radiochemical laboratories, one combined dark room - animal room - mechanical laboratory, and one counting room. Each radiochemical laboratory has four hoods suitable for handling radioactive materials. All laboratories are provided with conditioned air and have a filtered exhaust.

Experimental Tunnel

The Experimental Tunnel is an air-conditioned laboratory area, about $28 \times 36$ feet and 12 feet high, into which the cyclotron beam can be directed. The beam enters the room at its vertical center. Floor trenches distribute services throughout the room and these trenches connect directly 
to the cyclotron vault. An access corridor is provided for movement of equipment and targetry to and from the general laboratory area. Within the room a 3000-pound traveling bridge crane is provided to aid in the movement of equipment.

Shielding is provided by an earth mound which is 4 feet thick over the ceiling and extends out past the side walls before tapering to the normal ground contour.

An over-all external view of the cyclotron building is shown in Fig. 20.

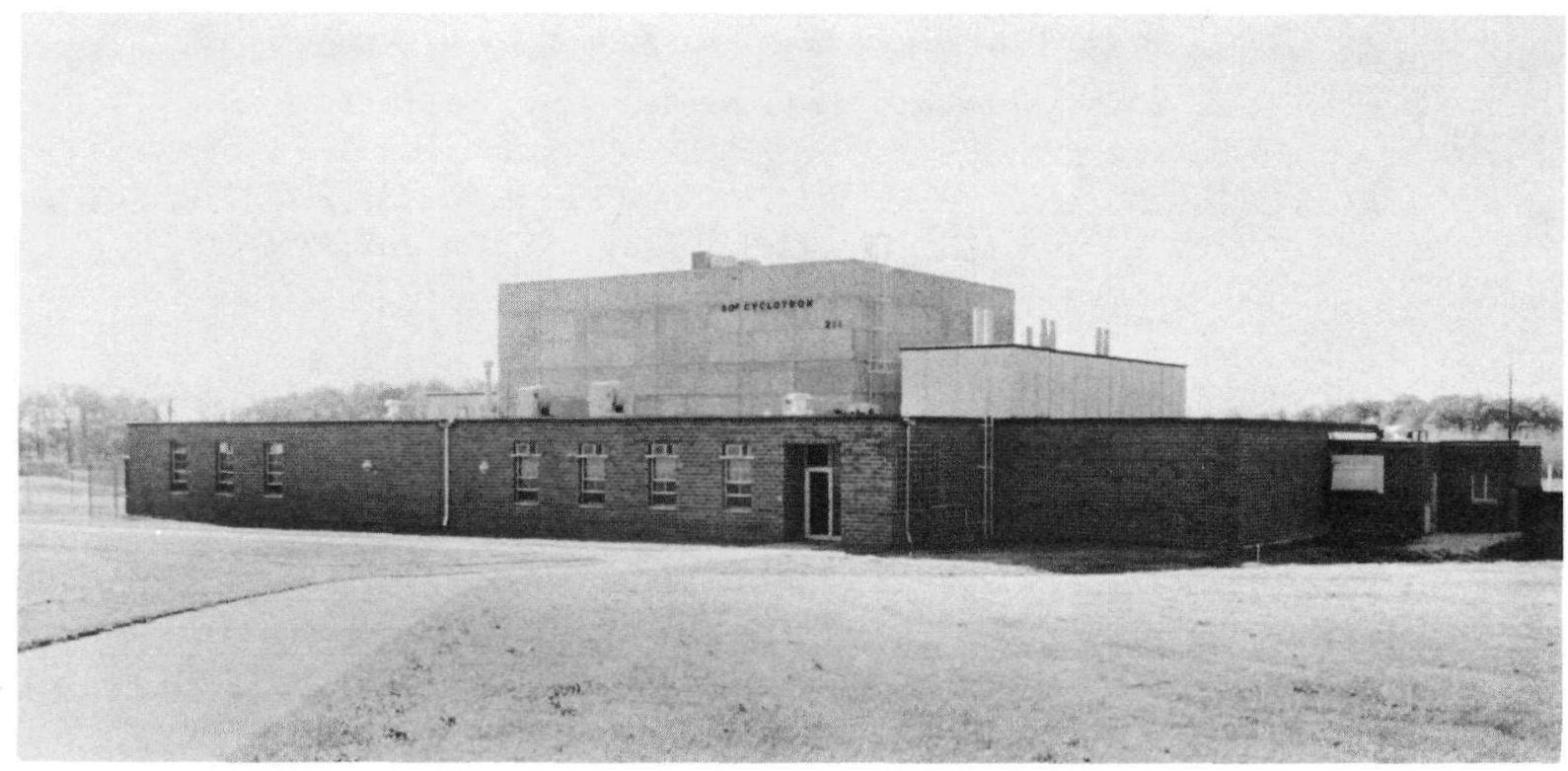

Fig. 20 Cyclotron building. 


\section{ACKNOWLEDGMENTS}

The authors wish to recognize the following for their over-all contributions to the cyclotron project: J. J. Livingood, W. W. Salisbury, C. Everson, G. W. Parker, G. Price, R. R. Weeks, and the former cyclotron group at the Collins Radio Company for their excellent performance in the design, construction and installation of the cyclotron: J. P. FitzPatrick for the development of the cyclotron housing and facilities; S. R. Rocklin, as an ANL representative, actively participated in the construction, installation and test of the machine; and to O. C. Simpson for his initial founding of the cyclotron project and his unerring guidance throughout the development and operation of the machine.

\section{REFERENCES}

1. B. L. Cohen, The Theory of the Fixed-Frequency Cyclotron, Rev. Sci. Instr., 24, 589-601 (1953).

2. G. Schrank, Energy Control for External Cyclotron Beams, Rev. Sci. Instr., 26, 677-680 (1955).

3. Soller, Starr, and Valley, Cathode Ray Tube Displays, 22, Radiation Laboratory Series, Ed. 1, 333-4, McGraw-Hill, 1948.

4. Tochilin, Ross, Shumway, Kohler, and Golden, Cyclotron Neutron and Gamma-ray Dosimetry for Animal Irradiation Studies, USNR DL-TR-25 (1954).

5. D. J. Hughes and J. N. Harvey, Neutron Cross Sections, BNL-325, 105 (1955). 


\section{ARGONNE CYCLOTRON SUMMARY}

The ANL cyclotron is a fixed-frequency type of machine. Resonance tuning is accomplished by varying the radiofrequency with the magnetic field held constant.

Flux Data

Deflected deuteron beam energy

Deflected beam intensity (nominal)
(a) deuterons
(b) alphas
(c) molecular hydrogen $\left(\mathrm{H}_{2}^{+}\right)$

Deflected deuteron beam density (nominal)

Deflected and focused beam densities

(a) deuterons 20-30 $\mu \mathrm{amp}$

(b) alphas 10-15 $\mu \mathrm{amp}$

(c) $\mathrm{H}_{2}^{+}$(estimated 10-15 $\mu \mathrm{amp}$

Neutron flux $(\mathrm{d}-\mathrm{xn}, \mathrm{Be}), \mathrm{E}_{\mathrm{n}}>2 \mathrm{Mev}$

Internal deuteron beam intensity,

(deflected beam x 3)

Performance Data for Deuteron Acceleration

Energy

Magnetic field, center

Frequency

Dee to dee voltage

Plate power input

Deflector voltage

Vacuum

Deflected beam

Cooling

Cyclotron cooling

Vacuum

Chamber, volume

Diffusion pumps

Forepumps

Operating vacuum

\section{$21.6 \mathrm{Mev}$}

$200 \mu \mathrm{amp}$

$100 \mu \mathrm{amp}$

$100 \mu \mathrm{amp}$

$20 \mu \mathrm{amp} / \mathrm{cm}^{2}$

200-300 $\mu \mathrm{amp} / \mathrm{cm}^{2}$

$100-150 \mu \mathrm{amp} / \mathrm{cm}^{2}$

$100-150 \mu \mathrm{amp}$

$2 \times 10^{9} \mathrm{n} / \mathrm{sec} / \mathrm{cm}^{2} / \mu \mathrm{amp}$

$600 \mu \mathrm{amp}$

$21.6 \mathrm{Mev}$

14.9 kgauss

$11.200 \mathrm{Mc} / \mathrm{sec}$

$240 \mathrm{kv}$

$105 \mathrm{kw}$

$75 \mathrm{kv}$

$3 \times 10^{-6} \mathrm{~mm} \mathrm{Hg}$

$200 \mu \mathrm{amp}$

Water, demineralized
$300 \mathrm{cu} \mathrm{ft}$

2 16-inch DPI type, MCF 5000

2 Kinney type, $100 \mathrm{cfm}$ and $300 \mathrm{cfm}$

2 to $9 \times 10^{-6} \mathrm{~mm} \mathrm{Hg}$ 
Magnet - Double York Design

Weight

Magnet pole tip diameter

Lids, acceleration chamber, diameter

Magnet pole gap

Lids, acceleration chamber, thickness

Shimming gap, two external

Gap inside vacuum

Effective gap

Magnet field, center

Magnet field drop off, $R=25-3 / 4$ inches

Field index at $25-3 / 4$ inch radius

Magnet field stability

Magnet coils, 2

Magnet power (390 amp, 145.5 volts)

Ion Source

Chimney, hooded type

Chimney aperture

Filament, hair pin

Filament power

$\underline{\text { Radiofrequency System }}$

Dee system

Dee height

Internal dee height, with water tubing

Dee entrance gap

Dee distance to ground plane

Unloaded system Q

Os cillator

\section{Amplifier}

Oscillator tube (provision for 2 in parallel)

Amplifier tube (provision for 2 in paralle1)

Power supply

Frequency tune range

Dee to dee voltage, operating maximum
265 tons

62 inches

60 inches

22 inches

5 inches

each 1 inch

10 inches

9 inches

14.9 kgauss

$2.6 \%$

$\mathrm{n}=\operatorname{approx} 0.3$

1 part in 20,000

1099 total turns

$56.7 \mathrm{kw}$

0,302 -inch OD, $1 / 4$-inch

ID, graphite

$3 / 32 \times 7 / 32$ inch long

1/8-inch diam., Ta

$220 \mathrm{kc} / \mathrm{sec}$

Twin

4 inches

$2-3 / 4$ inches

$2 \frac{1}{2}$ inches

$2 \frac{1}{2}$ inches

10,000

self-excited, push-pull, tuned plate, untuned grid, cathodes at $r f$ ground

Push-pull, grounded grid

type

Machlett - ML 356

Machlett - ML 5681

$400 \mathrm{kw}$ maximum

$1 \mathrm{Mc} / \mathrm{sec}$

$310 \mathrm{kv}$ peak 
Deflector

Type

Operating deflector voltage (nominal)

Deflector system length

Entrance radius of deflector system

Orbital radius increase

DC

$75 \mathrm{kv}$

95 degrees

25.75 inches

$17.5 \%$

Cyclotron Vault

Size

$40 \times 50 \mathrm{ft}, 28 \mathrm{ft}$ high

Shielding

$7 \mathrm{ft}$ of $150-\mathrm{lb} / \mathrm{cu} \mathrm{ft}$ concrete

Doors, two

Hydraulic, vertical lift 


\section{APPENDIX II}

\section{SUPPLIERS AND FABRICATORS}

The following is a list of the suppliers and fabricators of major cyclotron components.

Magnet System

(a) Magnet:

(b) Motor-Generator:

(c) Field Stabilizer (Modified Model F-6 Fluxmeter)

(d) Coil Conductors:

(e) Coil Winding:

\section{Radiofrequency System}

(a) Amplifier and Oscillator Tubes: ML 5681 and ML 356

(b) DC Power Supply:

(c) Dee System:

(d) Oscillator-Amplifier:

\section{Vacuum System}

(a) Diffusion Pumps, Mechanical Pumps, and Valving:

(b) Vacuum Envelope Fabrication:

1. VTO and Acceleration Chamber:

2. Obround Section:

3. Transition Section:
Carnegie-Illinois Steel

Corporation, Pittsburgh, $\mathrm{Pa}$.

General Electric Company

Varian Associates

Palo Alto, Calif.

Aluminum Import Corporation, agents for Aluminum Company of Canada, New York, N. Y.

Collins Radio Company

Cedar Rapids, Iowa

Machlett Laboratories, Inc. Springdale, Conn.

Westinghouse Electric Corp.

Fabricated by Brighton

Copper Works, Inc.

Cincinnati, Ohio

Collins Radio Company

Cedar Rapis, Iowa

Distillation Products, Inc.

(Formerly Eastman

Kodak Co. now

Consolidated Electro-

dynamics Corp.)

The Iowa Mfg. Co. Cedar Rapids, Iowa

F. H. Langsenkamp and Co. Indianapolis, Ind.

Brighton Copper Works, Inc. Cincinnati, Ohio 
(c) Material for Acceleration Chamber: (16-14 chrome nickel stainless steel)

Deflector System

Power Supply:
Allegheny Ludlum Steel Corp. Pittsburgh, $\mathrm{Pa}$,

Beta Electric Corporation New York, N. Y. 